\title{
A novel approach to the functional classification of retinal ganglion cells
}

\author{
Abbreviated title: DREADD for RGC classification \\ Gerrit Hilgen ${ }^{1,2 *}$, Evgenia Kartsaki ${ }^{1,3}$, Viktoriia Kartysh ${ }^{1,4,5}$, Bruno Cessac $^{3}$, Evelyne \\ Sernagor ${ }^{+*}$ \\ ${ }^{1}$ Biosciences Institute, Newcastle University, Newcastle upon Tyne, UK \\ ${ }^{2}$ Health \& Life Sciences, Applied Sciences, Northumbria University, Newcastle upon Tyne UK \\ ${ }^{3}$ Université Côte d'Azur, Inria, Biovision team and Neuromod Institute, Sophia Antipolis Cedex, $F$ \\ ${ }^{4}$ Ludwig Boltzmann Institute for Rare and Undiagnosed Diseases (LBI-RUD), 1090 Vienna, AT \\ ${ }^{5}$ Research Centre for Molecular Medicine (CeMM) of the Austrian Academy of Sciences, 1090 \\ Vienna, $A T$
}

*Corresponding author: gerrit.hilgen@ncl.ac.uk; evelyne.sernagor@ncl.ac.uk

Financial interests or conflicts of interest: The authors declare no competing financial interests 


\section{Abstract}

2 Retinal neurones come in remarkable diversity based on structure, function and genetic

3 identity. Classifying these cells is a challenging task, requiring multimodal methodology. Here,

4 we introduce a novel approach for retinal ganglion cell (RGC) classification, based on

5 pharmacogenetics combined with immunohistochemistry and large-scale retinal electrophysiology. Our novel strategy allows grouping of cells sharing gene expression and understanding how these cell classes respond to basic and complex visual scenes. Our approach consists of increasing the firing level of RGCs co-expressing a certain gene (Scnn1a or Grik4) using excitatory DREADDs (Designer Receptors Exclusively Activated by Designer Drugs) and then correlate the location of these cells with post hoc immunostaining, to unequivocally characterise anatomical and functional features of these two groups. We grouped these isolated RGC responses into multiple clusters based on the similarity of their spike trains. With our approach, combined with immunohistochemistry, we were able to extend the pre-existing list of Grik4 expressing RGC types to a total of 8 and, for the first time, we provide a phenotypical description of 14 Scnn1a-expressing RGCs. The insights and methods gained here can guide not only RGC classification but neuronal classification challenges in other brain regions as well.

\section{Keywords}

DREADD, Grik4, Scnn1a, retinal ganglion cells, multielectrode array, classification

\section{Introduction}

The retina contains two types of photoreceptors, rods for dim light and cones for daylight and colour vision. Furthermore, cone-contacting bipolar cells can be divided into ON and OFF types and further subdivided into more than a dozen different subpopulations (1). These parallel processed channels are further divided into a variety of functional output channels, so-called retinal ganglion cells (RGCs), which encode different features of the visual 
environment. There are $\sim 1$ million RGCs in the human retina and $\sim 45,000$ in the mouse retina $(2,3)$, integrating visual information processed from photoreceptors down the retinal neural network. Different types of RGCs extract very specific features from the visual scenery (4). This code is transmitted to postsynaptic targets in the brain, leading to visual perception. At present, more than 40 RGC types have been identified in the mouse retina $(5,6)$. RGC classification is typically based on common anatomical features $(7,8)$, responses to light $(5,9-$ $11)$ or on shared gene expression $(6,12-14)$. Classification based on gene expression is relatively recent, and the majority of RGC groups sharing specific genes have not been phenotyped yet.

Current approaches for functional characterization of RGC subpopulations at pan-retinal scale are limited. Multielectrode arrays (MEAs) allow high throughput simultaneous electrical recording from the RGC population at high spatiotemporal resolution (15). Here we use a CMOS (complementary metal-oxide-semiconductor) MEA system consisting of 4,096 electrodes $(2.67 \times 2.67 \mathrm{~mm})$, allowing us to record light responses from hundreds to thousands of RGCs simultaneously at pan-retinal level and near cellular resolution $(16,17)$. We selected two genes based on Cre lines availability, on the sparse expression distribution across the RGC layer and on their novelty for phenotypic characterization (Allen Mouse Brain Connectivity Atlas (2011)). Grik4 (glutamate receptor, ionotropic, kainate subunit 4, HGNC: 4582) expressing RGCs have already been partially described using a Grik4 Cre mouse line (18). The other gene we investigated is Scnn1a (non-voltage gated sodium channel, epithelial 1 subunit alpha, HGNC:10599). Scnn1a Cre-induced recombination (Scnn1a-Tg3-Cre line) is present in sparse Layer 4 neurones, mostly in the somatosensory cortex (19). Current knowledge of Scnn1a expressing RGCs in the retina is limited to the fact that their dendritic arbour stratifies in sublaminas S1 and S2 (OFF layers) and in sublamina S4 (ON layer) of the inner plexiform layer (13). Here, we crossbred Grik4 and Scnn1a Cre mice with DREADD flox mice to further investigate these RGC types. 
Designer Receptors Exclusively Activated by Designer Drugs (DREADDs) (20) technology is

a powerful new approach to pharmacologically dissect out the role of specific neuronal cell classes in network activity $(21,22)$. DREADDs are an engineered version of G-proteins that allow precise control of G-protein signalling pathways and can be activated with clozapine-Noxide (CNO), a "designer drug" with no endogenous receptors in the organism. Most commonly used DREADDs are excitatory (hM3Dq, triggering release of calcium from organelles leading to increase of intracellular concentration of free calcium and to membrane depolarization). In this study, we have generated Cre recombinase-mediated restricted expression of cell-specific DREADD (23) expression in either Grik4 or Scnn1a reporter lines. We have successfully isolated light-evoked responses in RGCs sharing either Scnn1a or Grik4 gene expression by combining excitatory DREADD activation, large-scale retinal CMOS MEA recording and post hoc labelling of DREADD-expressing RGCs. We grouped the RGC responses into multiple clusters based on the similarity of the spike trains they generate in response to a series of stationary stimuli. Our method was validated by successfully isolating existing Grik4-RGC types, but it also added several new candidates to the group. It provided novel classification for 14 subgroups of Scnn1a-RGCs.

To functionally validate RGC subgroups according to shared gene expression, we first established an immunohistochemical atlas of these cells. Building such a resource for Grik4 and Scnn1a expressing cells in the mouse retina is important for estimation of the RGC numbers and types in these two genetic pools. We used the intrinsic fluorescence signal of Grik4-DREADD (hereafter named Grik4) and Scnn1a-DREADD (hereafter named Scnn1a) cells to provide a detailed IHC map of Grik4 and Scnn1a expressing cells in retinal whole mounts and vertical sections. Each DREADD is tagged with hemagglutinin (HA) as well as mCitrine, allowing to visualize DREADD-expressing cells by immunofluorescence. We first investigated the distribution of Grik4 and Scnn1a cells in the ganglion cell layer (GCL) in retinal 

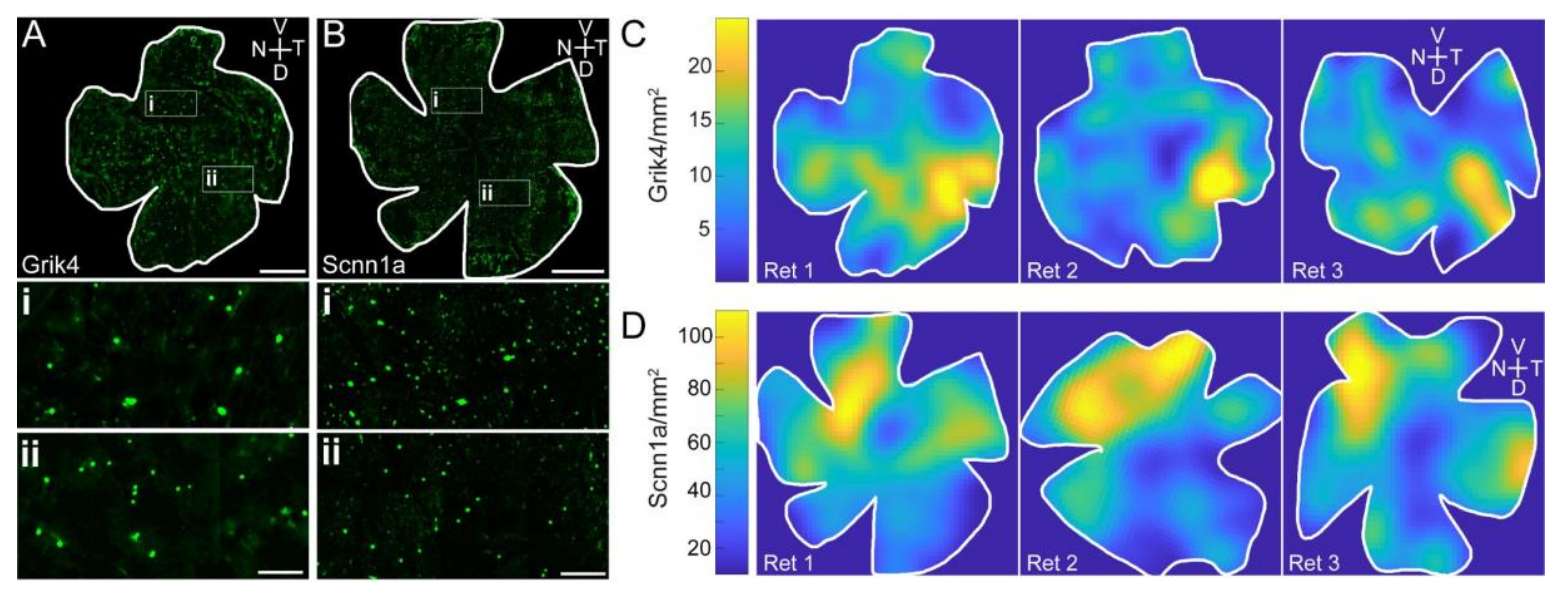

Figure 1: Grik4 and Scnn1a cells in the GCL are not homogeneously distributed. Whole mount antibody staining against Grik4 (A) and Scnn1a (B) DREADD GFP were imaged at the level of the GCL. All stained GFP cells were counted and the densities were calculated and presented in pseudocolors for 3 Grik4 $(C)$ and Scnn1a (D) retinas. $V=$ ventral, $T=$ temporal, $D=$ dorsal, $N=$ nasal. Scale bar $A, B=1 \mathrm{~mm}$; Scale bar $A, B$ insets $/ I=100 \mu \mathrm{m}$.

whole mounts using an antibody against Green Fluorescent Protein (GFP) to amplify the intrinsic mCitrine signal (Fig 1). Both lines exhibit sparse cellular distribution in the GCL, with Scnn1a cells significantly more abundant than Grik4 (Fig 1 A, B insets I and II). We calculated the cell densities in the GCL of three representative Grik4 (Fig 1 C) and Scnn1a (Fig 1 D) retinas. Grik4 and Scnn1a cell densities respectively vary between 10-25 and 40-100 cells $/ \mathrm{mm}^{2}$. Both pools exhibit non-even distributions. Grik4 cells are more prominent in the dorsal-temporal periphery (Fig $1 \mathrm{C}$, yellow areas), while Scnn1a cells are more prominent in the ventral-nasal periphery (Fig $1 \mathrm{D}$, yellow areas).

The GCL consists mainly of RGCs but it also contains displaced amacrine cells (dACs) and glial cells. We investigated whether dACs contribute to the pool of Grik4 and Scnn1a cells in the GCL. We used known specific RGC and amacrine cell (AC) markers to estimate the contribution of different RGC types in both gene pools. First, we double-labelled Grik4 and Scnn1a retinal vertical sections against GFP (Fig 2 A, B cyan) and RBPMS (Fig 2 A, B magenta), a selective marker for RGCs in the mammalian retina (24). More than $50 \%$ of the GFP labelled Grik4 cells in the GCL are RBPMS positive (Fig 2 A, arrows) whereas the other 

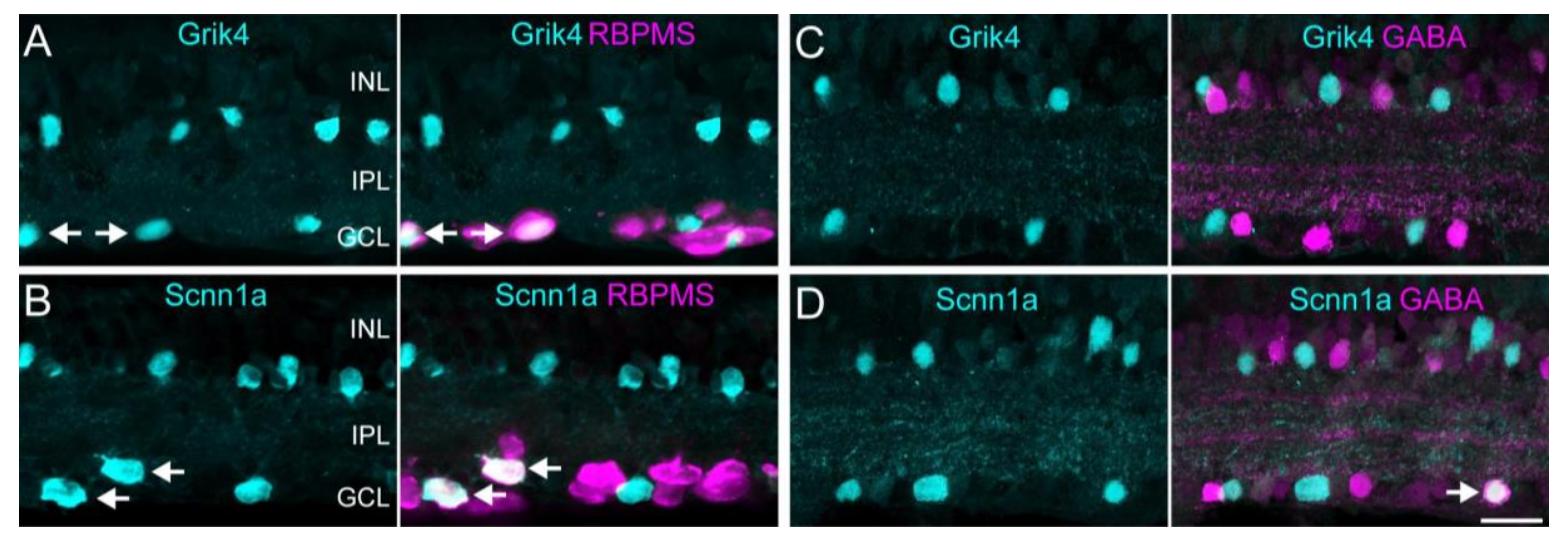

Figure 2: Grik4 and Scnn1a DREADD are expressed in RGCs and ACs. Vertical sections were stained for Grik4 (A, C, cyan) and Scnn1a (B, D, cyan) GFP. Sections were further co-labelled with RBPMS ( $A, B$, magenta), a marker for RGCs, and $G A B A$ ( $C, D$, magenta). $I N L=$ inner nuclear layer, IPL = inner plexiform layer, $G C L=$ ganglion cell layer. Scale bar in $D=20 \mu m$.

cells are likely dACs. In support, the somata of putative dACs in the GCL are relatively small,

which is a key feature of these cells. A similar pattern was found for Scnn1a cells in the GCL

but here, the majority of Scnn1a cells are RGCs (Fig 2 B, arrows). Sparsely distributed cells expressing either Grik4 (Fig 2 C, cyan) or Scnn1a (Fig 2 D, cyan) were present in the proximal inner nuclear layer (INL). These cells did not stain for RBPMS (Fig 2 A, B), confirming they are amacrine cells (ACs). Most AC types are GABAergic, hence we initially stained for GABA (Fig 2 C, D, magenta) and GFP in Grik4 and Scnn1a vertical sections. Interestingly, we did not find any GABA-positive Grik4 ACs (Fig 2 C). On the other hand, we occasionally found GABAergic Scnn1a cells in the INL or GCL (Fig 2 D, arrow). In conclusion, a major proportion of Grik4 and Scnn1a cells in the GCL are RGCs but both genes are also sparsely expressed in ACs in the INL and in dACs in the GCL. Further, GABA is not present in Grik4 cells, but it is in a very small population of Scnn1a expressing cells.

To further characterize the expression patterns of Scnn1a and Grik4 in RGCs and ACs, retinal sections were stained for GFP, RBPMS and for the well-described calcium-binding protein 

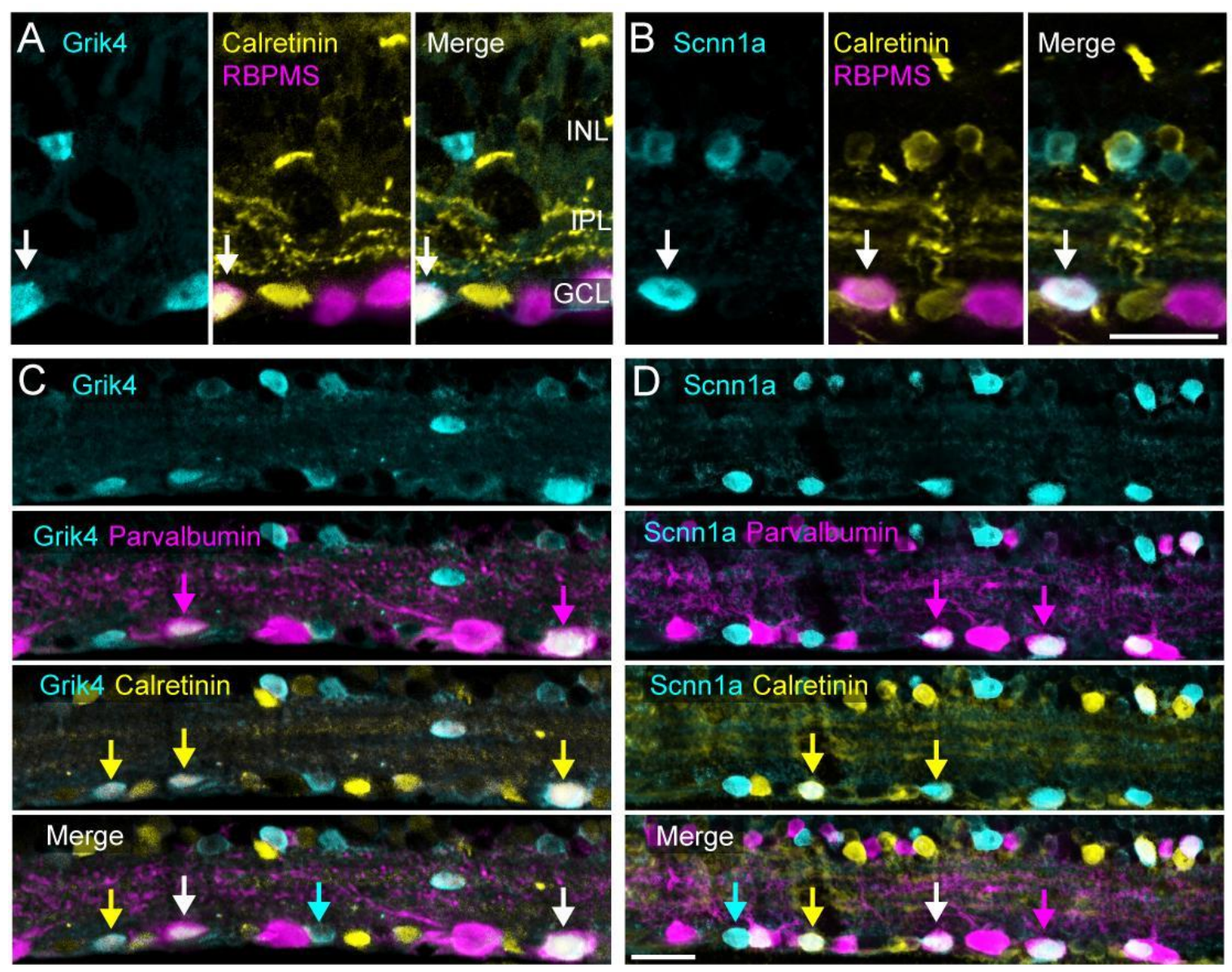

Figure 3: Grik4 and Scnn1a DREADD are expressed in multiple RGC types. Vertical sections of Grik4 and Scnn1a retinas were triple stained A, B) for GFP (cyan), RBPMS (magenta) and Calretinin (yellow) or C, D) GFP (cyan), Parvalbumin (magenta) and Calretinin (yellow). INL = inner nuclear layer, IPL = inner plexiform layer, GCL = ganglion cell layer. Scale bar in $D=20 \mu \mathrm{m}$.

112 in 8-14 different RGC types. Calretinin is also present in ACs and in 10 RGC types. In a first

113 set of experiments (Fig 3 A, B) we labelled respectively against GFP (cyan), RBPMS

114 (magenta) and Calretinin (yellow) in vertical sections of Grik4 (Fig 3 A) and Scnn1a (Fig 3 B)

115 retinas. For both retinas, we found a subset of Grik4 and Scnn1a RGCs that were

116 GFP/RBPMS/Calretinin positive (Fig 3 A, B arrows) and GFP/RBPMS positive cells, which

117 clearly demonstrates that there are at least two RGC types for each pool. We did not find any

118 Calretinin positive Grik4 ACs, but we did find some Calretinin positive Scnn1a ACs. For

119 technical reasons we were not able to combine RBPMS and Parvalbumin staining (both 120 antibodies were raised in the same species). To extend on these findings and to further 
investigate if the genetic pools of Grik4 and Scnn1a consist of more than two RGC types, we triple-labelled vertical sections (Fig 3 C, D) for GFP (cyan), Calretinin (yellow) and Parvalbumin (magenta). Our initial findings indicate that the majority of GFP cells in the GCL are RGCs. These experiments described below thus aimed to find out whether these GFP cells can be subdivided into smaller groups. We found that the population of Grik4 (Fig 3 C) expressing cells (cyan) in the GCL consists of at least three different types of cells: only GFP (Fig 3 C, cyan arrow), GFP/Calretinin (yellow arrow) and GFP/Calretinin/Parvalbumin (white arrows) cells. It is likely that these three different cell types reflect RGCs and not dACs because we did not find any putative Grik4 ACs in the INL expressing Calretinin and/or Parvalbumin.

For the pool of Scnn1a expressing cells in the GCL (Fig $3 \mathrm{D}$ ), we found four different types: those expressing only GFP (Fig 3 D, cyan arrow), GFP/Calretinin (yellow arrow), GFP/Parvalbumin (magenta arrow) and GFP/Calretinin/Parvalbumin (white arrow) cells. A fraction of the GFP positive ACs in the INL were positive for Calretinin, suggesting that some P/Calretinin and GFP/Calretinin/Parvalbumin cells in the GCL are potentially dACs. In summary, the pool of Grik4 and Scnn1a cells in the GCL respectively consists of at least three and four different RGC types. That information is important for the validation of our novel approach to the functional classification of these same RGCs.

We next identified Grik4 and Scnn1a RGCs according to the change of their spiking pattern following DREADD activation with CNO, and we grouped them into functional clusters based on response similarity. The IHC experiments revealed that DREADDs are expressed in several RGC types but also in ACs (albeit more sparsely). Hence, the first step to isolate Grik4 and Scnn1a expressing RGCs is to pre-identify cells that showed either a $50 \%$ (arbitrarily chosen) increase in spontaneous firing rate (Fig 4 A) or a 50\% increase of the Burst Index (Fig $4 \mathrm{~B}$ ) in the presence of CNO. That step is followed by correlating the physical position of these identified RGCs with micrographs of DREADD-GFP expressing cells in the GCL. This step was necessary because CNO also evoked activity in ACs which in turn altered spiking 
bioRxiv preprint doi: https://doi org/10.1101/2021.05.09.443323. this version posted July 8.2021 . The copyright holder for this preprint (which was not certified by peer review) is the author/funder, who has granted bioRxiv a license to display the preprint in perpetuity. It is made available under aCC-BY-NC-ND 4.0 International license.

148 unknown DREADD ACs with pharmacological agents resulted in up- and down regulated

149 spiking
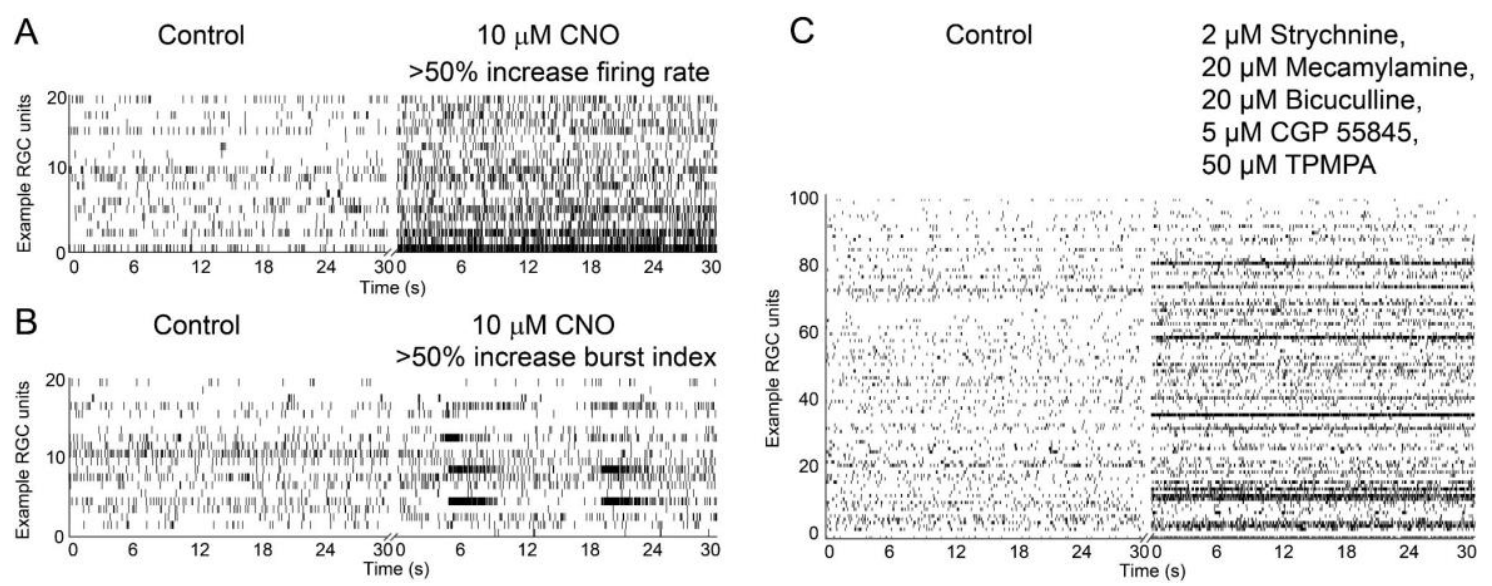

Figure 4: DREADD activation leads to spike pattern changes in RGCs. DREADDs in $R G C s$ can be activated with Clozapine $N$-oxide (CNO) and lead to an increase in firing frequency ( $A$, right half) and sometimes also in bursting activity ( $B$, right half). Similar activities can be evoked with an "allround" $A C$ neurotransmitter blocker (C) without CNO. The cocktail contains: $2 \mu \mathrm{M}$ Strychnine (glycine receptor antagonist), $20 \mu \mathrm{M}$ Mecamylamine (nicotinic acetylcholine receptor antagonist), $20 \mu M$ Bicuculline $\left(G A B A_{A}\right.$ antagonist), $5 \mu M$ CGP 55845 ((2S)-3-[[(1S) -1- (3,4-Dichlorophenyl)ethyl] amino -2- hydroxypropyl] (phenylmethyl) phosphinic acid hydrochloride, $G A B A_{B}$ antagonist), $50 \mu M$ TPMPA (1,2,5,6-Tetrahydropyridin-4-yl methylphosphinic acid, $G A B A_{C}$ antagonist). Plotted in $A, B$ are 20 Grik4 RGCs that showed a minimum of $50 \%$ change in firing frequency or bursting activity and in C 100 randomly selected

activities in almost all RGCS (Fig $4 \mathrm{C}$ ), hence it is not a suitable approach to isolate the DREADD RGCs. The process of correlating physical positions with structural imaging allowed us to unequivocally correlate anatomical and functional features of Grik4 and Scnn1a RGCs.

Here, we provide a brief exemplary description, using an identified Grik4 RGC (Fig 5), to show how we register GFP labelled cells with their spiking activity for unambiguous identification of Grik4 RGCs. Further technical details are available in the Method section. The spike localization cluster centre (magenta circle) is calculated for a pre-identified (see above) Grik4 RGC (Fig 5 B) using the spike interpolation algorithm in Herdingspikes2. In addition, electrical imaging confirmed the maximal current sink position (Fig $5 \mathrm{C}$, orange diamond) and visualized 

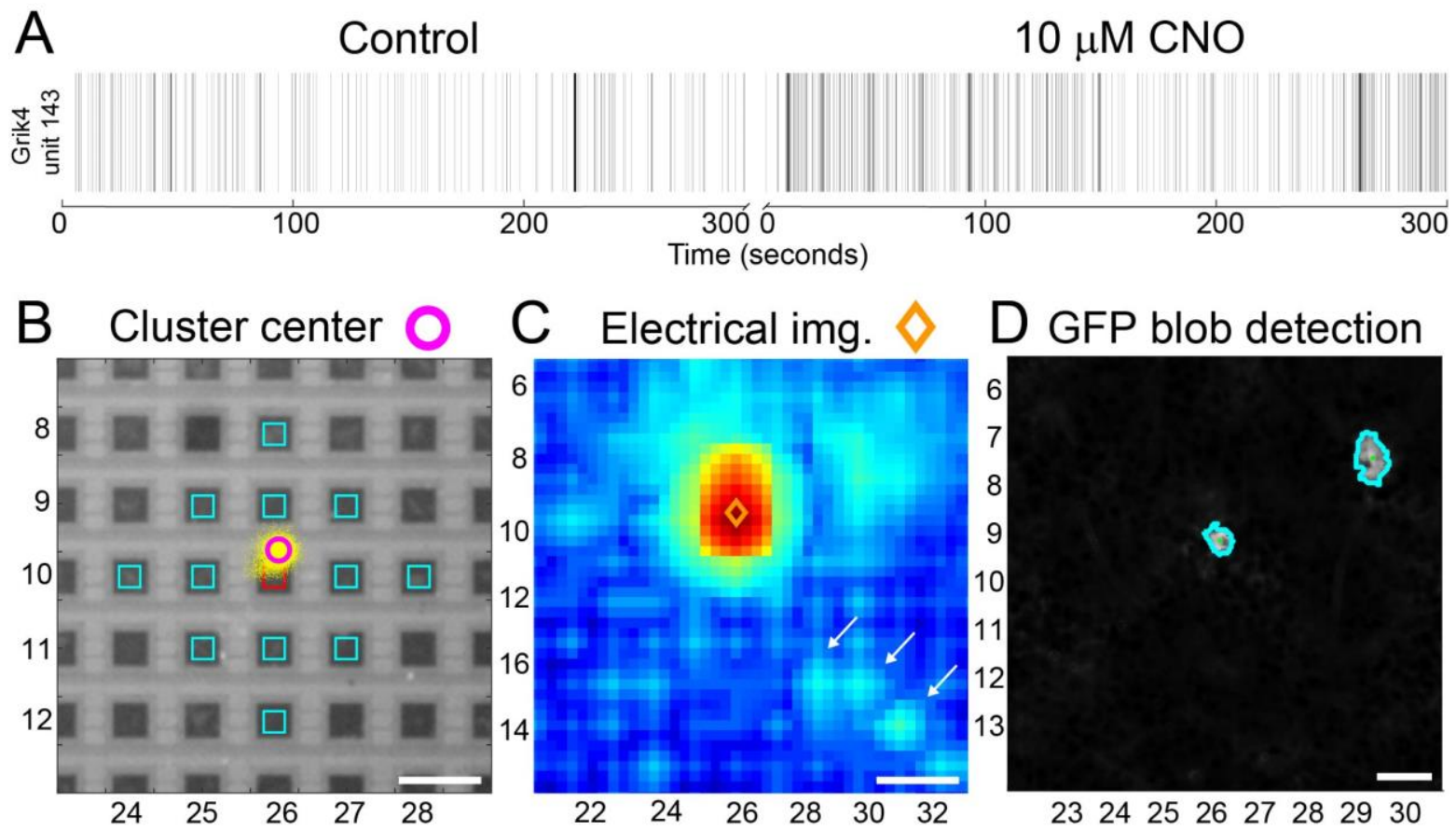

C Electrical img.

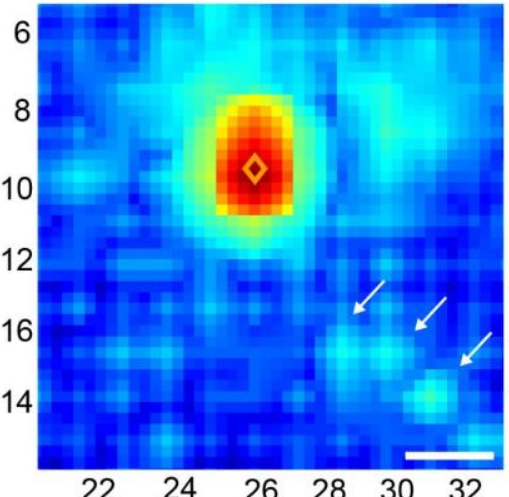

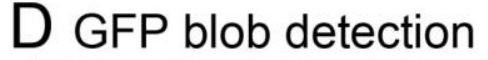

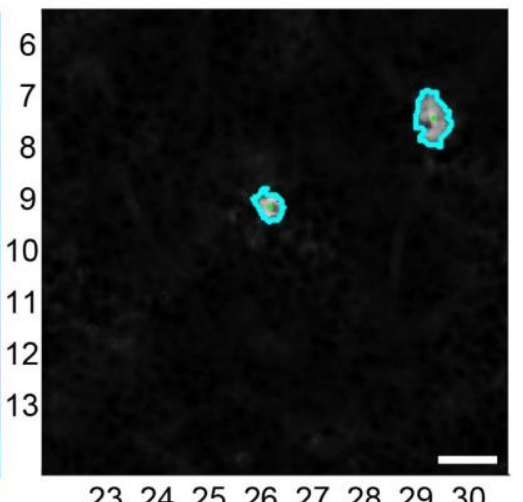

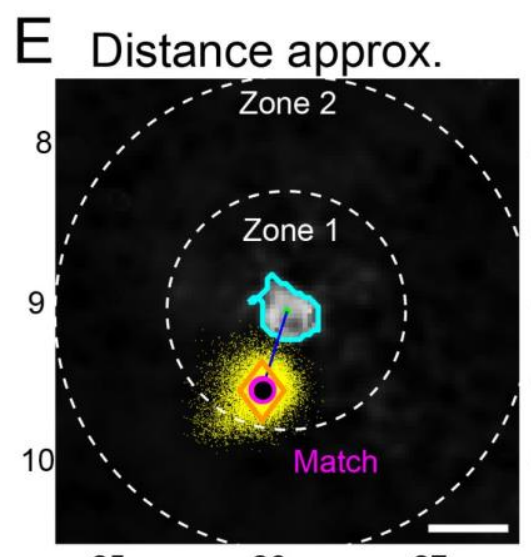

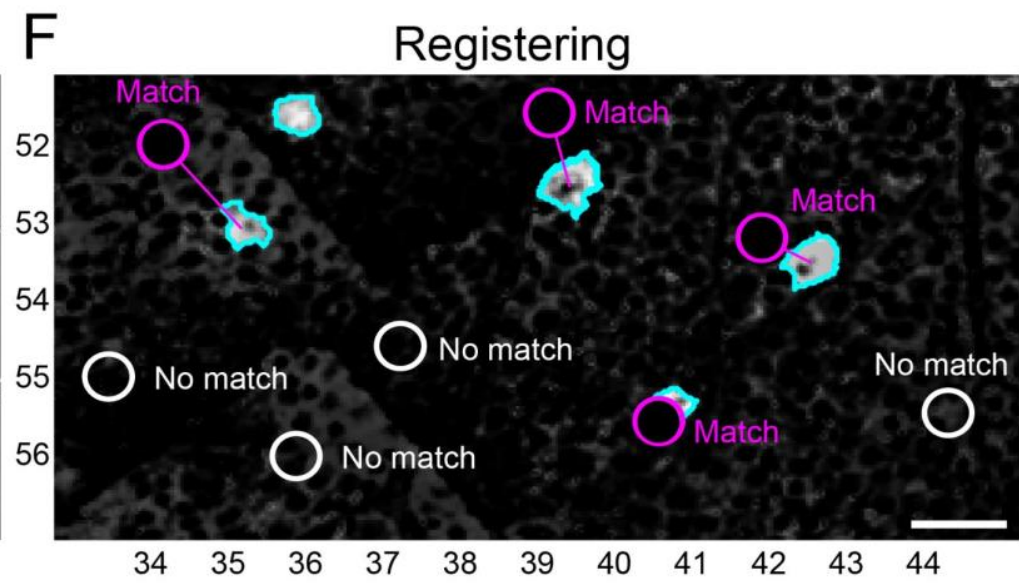

Figure 5: Registering GFP RGCs with nearby isolated spike centre clusters. The spike cluster centre $(B$, circle) and the electrical imaging $(C$, diamond) define the potential electrical source location of the isolated RGCs. Spike centres in close proximity to GFP labelled RGCs (D) were registered as potential DREADD-expressing RGCs (E, $F$, Match). Scale bars $A, C, F=40 \mu \mathrm{m} ; B=80 \mu \mathrm{m} ; E=20 \mu \mathrm{m}$.

putative axonal trajectories (Fig $5 \mathrm{C}$, arrows), thus helping to align the GFP cell structure with the electrical activity more precisely. Image segmentation techniques are used to threshold the GFP foreground from the background and a blob detection is applied to detect the outlines and centre of Grik4 and Scnn1a GFP positive cells in the GCL (Fig 5 D, green outline). Lastly, the $x$ and $y$ positions are converted to match with MEA images dimensions (Fig 5 E). Spikes originate from the axon initial segment (AIS) rather than from the cell body. Therefore, we 
expect the spike cluster centre to be slightly eccentric with respect to the soma itself. The exact location of the AIS in RGCs can be very close to the soma, or sometimes rather distant along the axon $(27,28)$. All the information from panels B-D is needed to estimate if a GFPexpressing cell corresponds to a nearby spike cluster centre. Two virtual circles with a radius of 30 and $60 \mu \mathrm{M}$ (arbitrary values) are drawn around a detected GFP blob centre (Fig $5 \mathrm{E}$ ), and spike cluster centres falling within one of these two zones are registered. From experience, we reached the conclusion that using the $60 \mu \mathrm{m}$ zone was sufficient to reliably determine whether an isolated spike cluster corresponds to a specific GFP-expressing cell. Such cases are referred to as "Match", and those falling outside these boundaries are classified as "No Match" (Fig 5 F, Fig 6 A, D). All other recorded spike units, that did not exhibit changes in spike behaviour in the presence of CNO, were labelled "RGC unit" (Fig 6 A, D) but not considered for further classification.

We successfully analysed 3 Grik4 and 5 Scnn1a retinas to register "Match" (Fig 6 A, D, magenta) and "No Match" (Fig 6 A, D, white) cells. Figure 6 A, D are representative examples from the cohort of all experiments. Note that the recording area is generally not completely covering the entire $64 \times 64$ array. In total, we identified 117 "Match" and 863 "No Match" RGC in the 3 Grik4 retinas (Fig 6 C) and 307 "Match" and 1066 "No Match" in the 5 Scnn1a retinas (Fig 6 F). We divided these RGCs according to their response preference for stationary (static, full field) and non-stationary images (moving bars for direction of orientation selectivity)). Briefly, cells that were exceeding a threshold value (see Methods) for their direction or orientation selectivity index (DSI and OSI, respectively) were classified as non-stationary (Fig $6 \mathrm{~B}, \mathrm{E})$. Figure 6 is showing an example for DSI grouping but we also grouped cells according to their OSI. In the following, we focus on "Match" Grik4 and Scnn1a RGCs only. A total of 78 Grik4 stationary and 41 non-stationary RGCs were collected (Fig 6 C). For Scnn1a, 180 stationary and 127 non-stationary RGCs were collected (Fig 6 F). However, most RGCs did exhibit changes in firing rate (increase or decrease) without revealing any GFP signals, hence they are unlikely to be Grik4 or Scnn1a RGCs (here called "No Match"). These cells are most 
192 likely other RGC types affected by either Grik4 or Scnn1a expressing ACs, and they

193 outnumber the "Match" RGCs. In summary, we successfully combined near pan-retinal
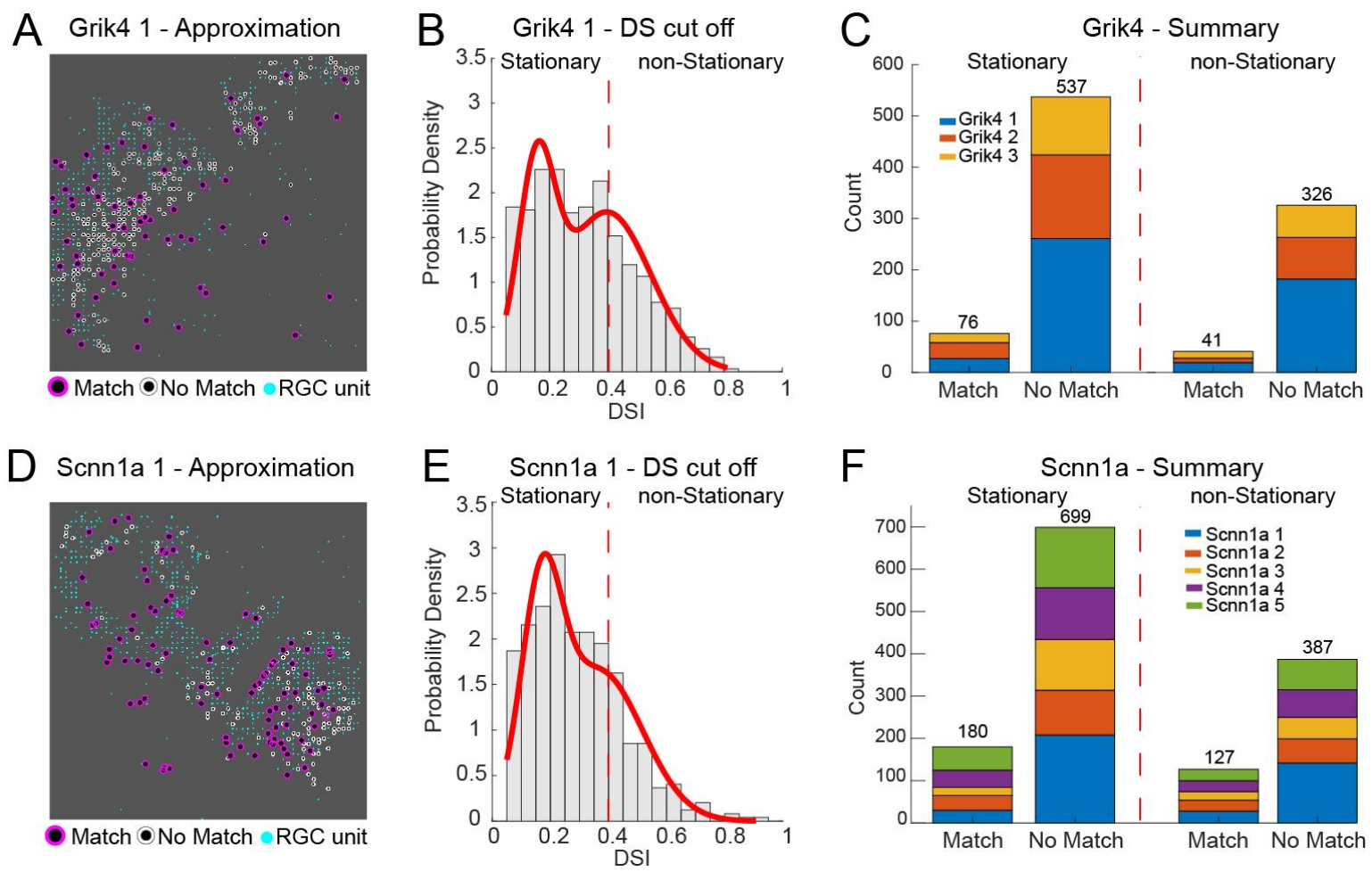

Figure 6: Dividing registered Grik4 and Scnn1a RGCs into stationary and non-stationary responders. Moving stimuli were used to estimate the direction selectivity index (DSI) of registered "Match" RGCs (Grik4 A, Scnn1a D, magenta). The DSI was plotted against the probability density (histogram) and fitted with two gaussians (B, E, red line). RGCs exceeding a set threshold ( $B, E$, dotted red line) were labelled "non-Stationary". The registered RGCs from all retinas were grouped into "non-Stationary" and "stationary" (C, F).

recordings with post hoc anatomical characterization and isolated GFP-positive Grik4 and Scnn1a RGCs with increased spiking or bursting activity in the presence of CNO.

After the successful registration of spikes with Grik4/Scnn1a GFP RGCs, the final step is to classify these cells into functional groups according to the nature of their responses to light. We recently described a non-parametric approach for RGC classification by using the SPIKE distance $(29,30)$ as a clustering metric $(10)$. In order to use that approach, it is necessary to have a stimulus that elicits responses simultaneously over the entire recording area. Here we used a chirp stimulus inspired from Baden et al (2016) (5) that elicits responses from all RGCs at the same time to pre-sort stationary and non-stationary RGCs (chirp, Fig 7 B, F, top) for 


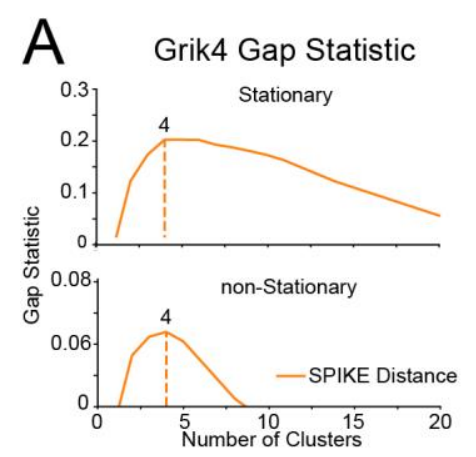

B Grik4 RGC types - Stationary
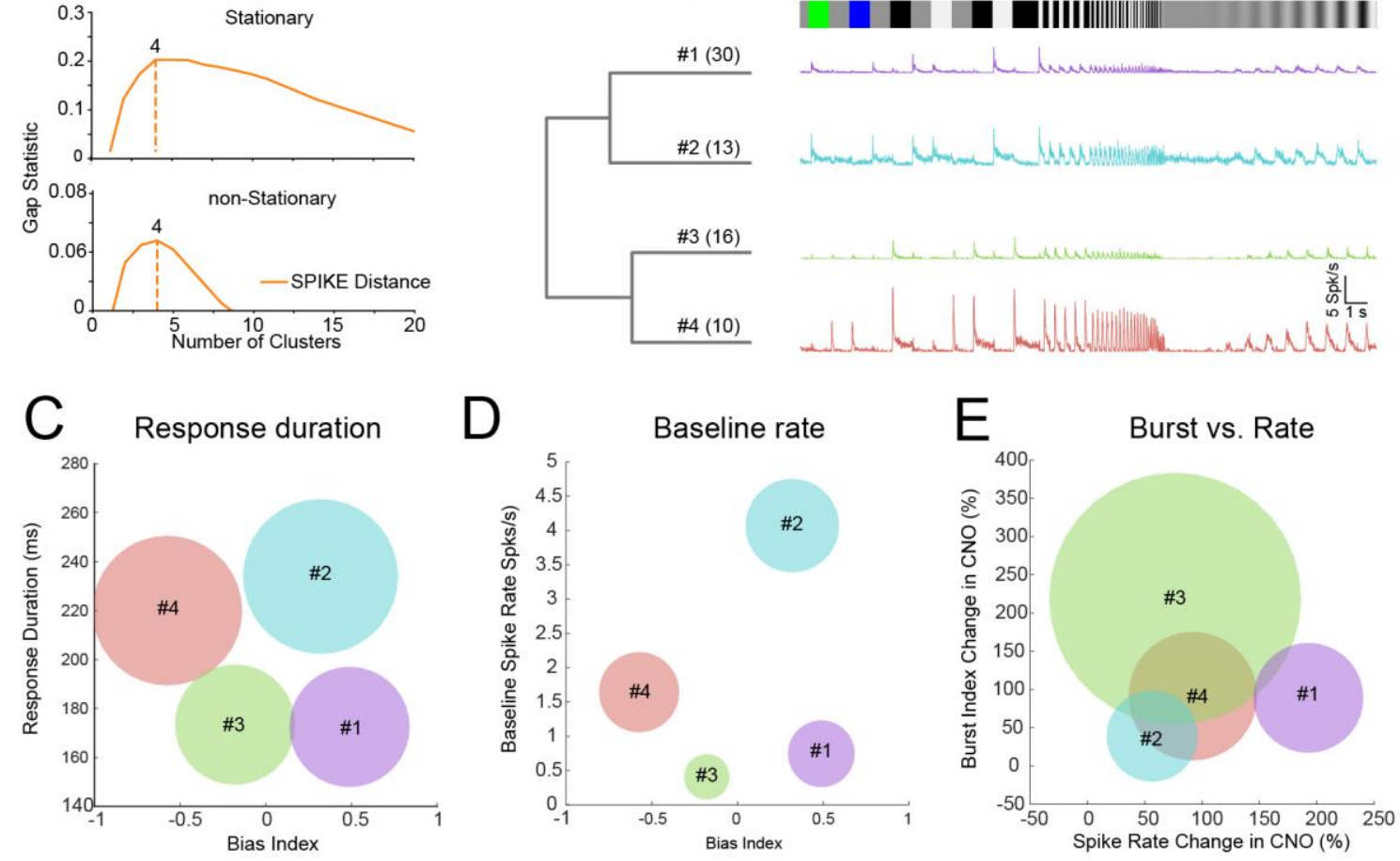

F Grik4 RGC types - non-Stationary
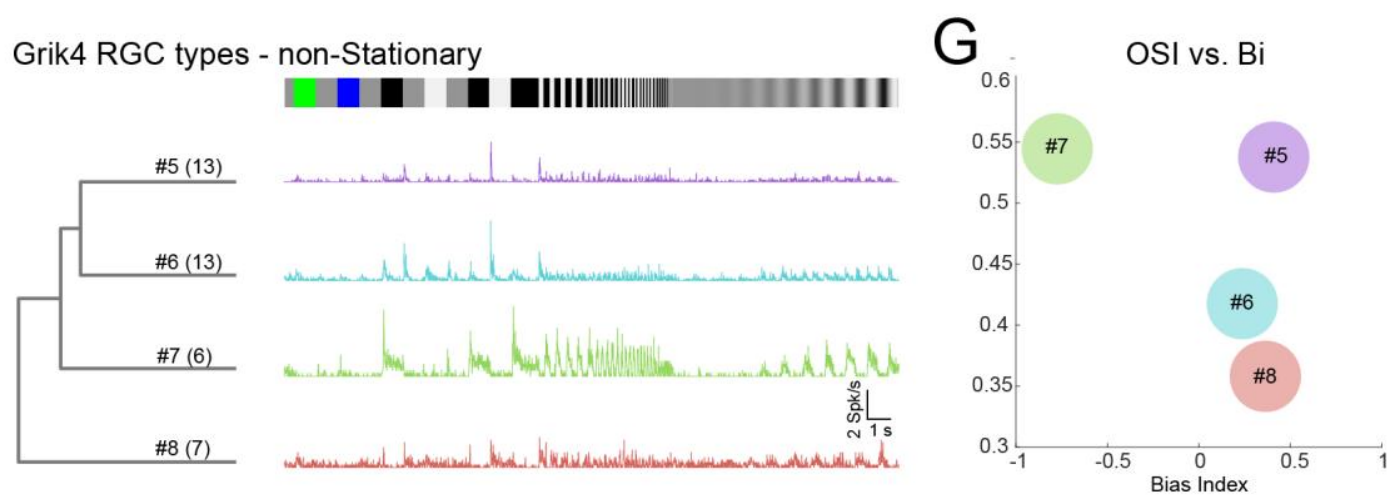

Figure 7: Clustering of Grik4 stationary and non-stationary RGC responses. RGC responses that showed a high spike train similarity for a chirp stimulus $(B, F)$ were grouped together using gap statistics $(A)$. For each RGC of the groups, the PSTH was calculated and the mean PSTH was plotted ( $B, F$, colored lines). The means for Bias Index $(C, D, G)$, Response Duration (C), Baseline Spiking (D), Burst change (E), Spike Rate change $(E)$ and orientation selectivity index $(O S I, G)$ index were scatter plotted and their standard deviations were used as the circle diameters.

SPIKE distance measure and hierarchical agglomerative clustering. We manually validated our detected clusters by grouping several response parameters, e.g. bias index (ON, ON-OFF or OFF) or response duration (transient or sustained), from the chirp and moving bars (for example Fig 7 C-E, G). Manual grouping was only feasible because the expected cluster 
numbers for Grik4 and Scnn1a were small (respectively 3 and 4 according to our IHC analyses). The pairwise SPIKE distances were determined from all trials of the chirp stimulus and the resulting distance matrix of stationary and non-stationary RGCs was clustered with a hierarchical clustering algorithm followed by the construction of a dendrogram as shown in Jouty et al., 2018 (10). To find the optimal number of clusters for stationary and non-stationary SPIKE distances we used gap statistics $(10,31)$. For stationary and non-stationary RGCs, gap statistics estimated four response clusters of Grik4 RGCs (Fig 7 A). Additional response parameters were extracted from the chirp peri-stimulus time histogram (PSTH) e.g., bias index or response duration of these 4 stationary RGC types. We found potentially $\mathrm{ON}$ transient (\#1, $\mathrm{n}=30)$, ON sustained $(\# 2, \mathrm{n}=13)$, ON-OFF $(\# 3, \mathrm{n}=16)$ and OFF sustained $(\# 4, \mathrm{n}=10)$ response types. Some RGC units were discarded during the process of SPIKE distance grouping as they showed a low signal-to-noise ratio i.e., high response variability (10). To validate these four detected clusters, we plotted the mean bias index against the mean response duration from all RGCs in a cluster (Fig $7 \mathrm{C}$ ), revealing four distinct groups that corresponded to the confirmed stationary RGC types. Moreover, spontaneous activity follows very specific patterns for certain RGC types and can therefore help classification. Plotting the mean Bias Index against mean spontaneous firing rate (baseline firing) revealed that the ON sustained cluster \#2 (Fig 7 B, C, cluster 2) exhibited a very strong baseline firing rate (Fig 7 D). The same plot also shows that the three other RGC types have a moderate baseline firing rate and further confirmed the 4 well separated RGC types. Whether the spontaneous firing rate becomes burstier or simply increases monotonously in the presence of CNO can be used to further group RGCs into clusters (Fig $7 \mathrm{E}$ ). Interestingly, the effect of CNO on cluster \#2 is minimal (Fig 7 E) whereas it is maximal for cluster \#3 (Fig 7 E). The non-stationary RGCs barely responded to the chirp stimulus (Fig $7 \mathrm{~F}$, scale bar) but that response was, albeit modest, reliable and unique for the different clusters. We used the orientation (OS) and direction selectivity (DS) index in addition to the chirp PSTH parameters to define the four nonstationary Grik4 clusters (Fig 7 F, G). We found ON - OS (\#5, n = 13), ON-OFF - DS (\#6, n = $23413 ; \# 8, n=7)$ and OFF - OS (\#7, n=6) response groups in the pool of non-stationary Grik4 
235 RGCs. The mean DS index was almost identical for these 4 groups; hence we used the OS 236 index for manual validation. While the ON - OS (\#5) and the OFF - OS (\#7) are clearly 237 distinguishable from each other, the difference is less pronounced between the two ON-OFF 238 - DS clusters (\#6 \& \#8). They have a similar mean BI, but Cluster 6 tends to be marginally 239 more OS (Fig $7 \mathrm{G}$ ). Clusters 6 and 8 would therefore need further evaluation to determine 240 whether they are truly different RGC types. In summary (Table 1), we found 4 stationary RGCs types and most likely 3, non-stationary RGC types that share the Grik4 gene pool.

\begin{tabular}{|c|l|c|l|}
\hline $\begin{array}{c}\text { Grik 4 } \\
\text { Cluster }\end{array}$ & \multicolumn{1}{|c|}{ Grik 4 stationary } & $\begin{array}{c}\text { Grik 4 } \\
\text { Cluster }\end{array}$ & \multicolumn{1}{c|}{ Grik4 non-stationary } \\
\hline$\# 1$ & G20 ON high freq after Baden et al., 2016 & $\# 5$ & $\begin{array}{l}\text { G17 ON local trans OS after Baden et al., } \\
2016\end{array}$ \\
\hline$\# 2$ & $\begin{array}{l}\text { G22 ON sustained after Baden et al., } \\
2016 ; \\
\text { Putative PixON after Johnson et al., 2018 }\end{array}$ & $\# 6$ & $\begin{array}{l}\text { G12 ON-OFF DS1 after Baden et al., 2016; } \\
\text { Vaney, Sivyer \& Taylor, 2012; } \\
\text { Temporal, dorsal cluster 10, 16, 24 after } \\
\text { Tran et al., 2019 }\end{array}$ \\
\hline$\# 3$ & $\begin{array}{l}\text { G11 ON-OFF local after Baden et al., } \\
2016 ; \\
\text { Putative HD1/2 after Jacoby \& Schwartz } \\
2017\end{array}$ & $\begin{array}{l}\# 7 \\
\text { G5 OFF alpha sustained after Baden et } \\
\text { al., 2016; Krieger et al., 2017 } \\
\text { Cluster 42 after Tran et al., 2019 }\end{array}$ & $\begin{array}{l}\text { G4 OFF slow after Baden et al., 2016; } \\
\text { Putative F-midi OFF after Rousso et al., } \\
2017 ; \\
\text { Cluster 28 after Tran et al., 2019 }\end{array}$ \\
\hline$\# 4$ & $\begin{array}{l}\text { G12 ON-OFF DS1 after Baden et al., 2016; } \\
\text { Vaney, Sivyer \& Taylor, 2012 }\end{array}$ \\
\hline
\end{tabular}

Table 1: Summary of identified Grik4 clusters and potential matches with existing literature. NB these are suggestions.

242 We proceeded in a similar way with stationary and non-stationary registered Scnn1a RGCs

243 (Fig 8). Gap statistics suggested 7 clusters for both groups (Fig 8 A). The dendrogram of the 244 chirp PSTH consists of ON transient (\#1, $n=30 ; \# 2, n=27 ; \# 3, n=47)$, ON sustained (\#6, $n$ $245=16 ; \# 7, \mathrm{n}=12)$, ON-OFF $(\# 5, \mathrm{n}=15)$ and OFF $(\# 4, \mathrm{n}=28)$ like response for Scnn1a RGC 246 types (Fig 8 B). Further analysis revealed that the ON sustained (\#7), OFF (\#4) and ON-OFF 247 (\#5) response parameters (Fig 8 C - Bias Index vs Response Duration; Fig 8 D - Bias Index 248 vs Baseline) were clearly distinct from each other. At the same time, the distinction is less 
A Scnn1a Gap Statistic

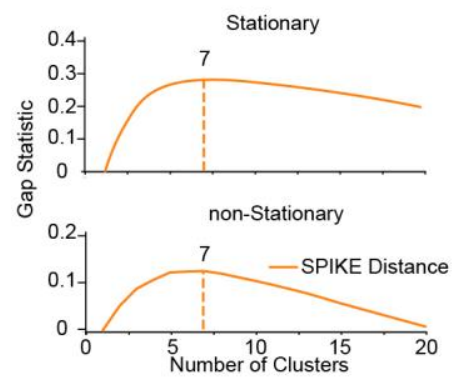

C

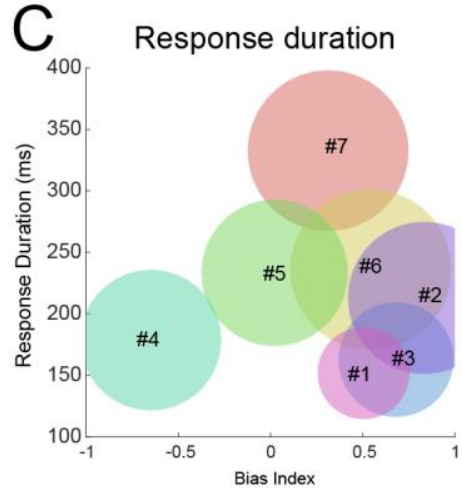

F Scnn1a RGC types - non-Stationary
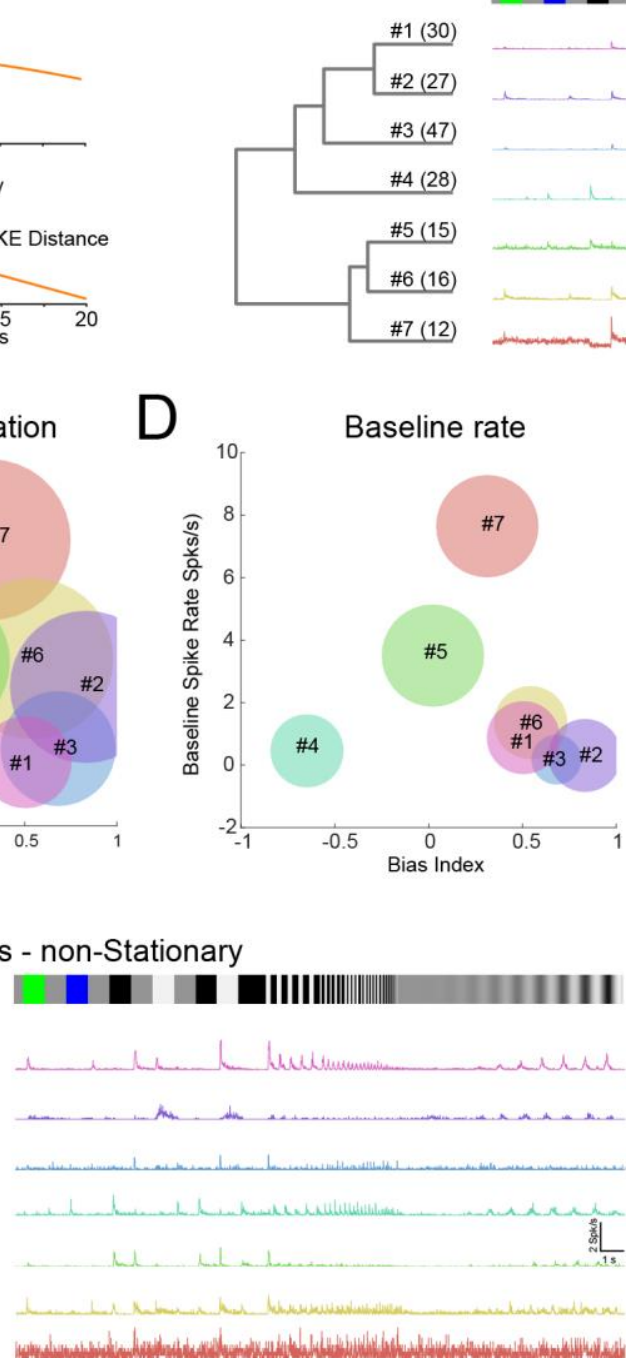

D

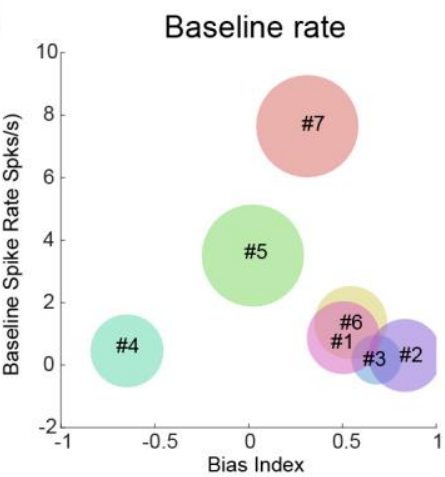

B scnn1a RGC types - Stationary

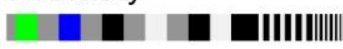
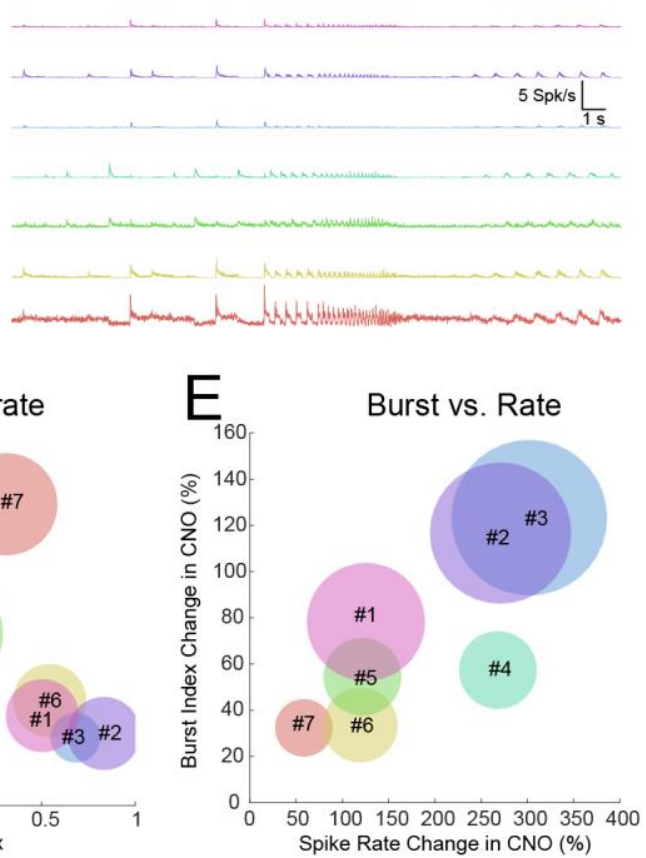

$G$

OSI vs. BI

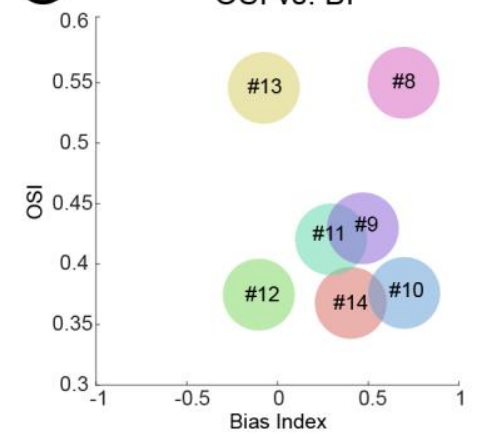

Figure 8: Clustering of Scnn1a stationary and non-stationary RGC responses. RGC responses that showed a high spike train similarity for a chirp stimulus $(B, F)$ were grouped together using gap statistics (A). For each RGC of the groups, the PSTH was calculated and the mean PSTH was plotted ( $B, F$, colored lines). The means for Bias Index (C, D, G), Response Duration (C), Baseline Spiking (D), Burst change (E), Spike Rate change (E) and orientation selectivity index (OSI, G) index were scatter plotted and their standard deviations were used as the circle diameters. 
$252(\# 12, n=28 ; \# 14, n=2)$, ON-OFF - OS (\#13, $n=13), \mathrm{ON}-\mathrm{DS}(\# 9, \mathrm{n}=8 ; \# 10, \mathrm{n}=12)$ and

253 ON - OS (\#8, $n=29)$ like responses. Although there was some overlap between certain 254 clusters (\#9, \#10,\#11, \#14) when plotting the Bias Index and OS index means (Fig 8 G), their 255 chirp PSTH plots were substantially different, suggesting that these cells do belong to distinct 256 functional groups. Therefore, it is likely that the Scnn1a RGC pool consists of several DS and 257 OS cells which will necessitate further investigation to establish their basic functional 258 differences. In summary (Table 2), we found a minimum of four stationary and a maximum of 259 seven non-stationary Scnn1a RGC types.

\begin{tabular}{|c|l|c|l|}
\hline $\begin{array}{c}\text { Scnn1a } \\
\text { Cluster }\end{array}$ & \multicolumn{1}{|c|}{ Scnn1a stationary } & $\begin{array}{l}\text { Scnn1a } \\
\text { Cluster }\end{array}$ & \multicolumn{1}{|c|}{ Scnn1a non-stationary } \\
\hline$\# 1$ & G18 ON trans after Baden et al., 2016 & $\# 8$ & $\begin{array}{l}\text { G17 ON trans (OS) after Baden et al., } \\
2016\end{array}$ \\
\hline$\# 2$ & G18 ON trans after Baden et al., 2016 & $\# 9$ & $\begin{array}{l}\text { G26 ON DS sustained 2 after Baden et al., } \\
2016\end{array}$ \\
\hline$\# 3$ & G18 ON trans after Baden et al., 2016 & $\# 10$ & $?$ \\
\hline$\# 4$ & $\begin{array}{l}\text { G8 OFF alpha trans after Baden et al., } \\
\text { 2016; Krieger et al., 2017; } \\
\text { Cluster 45 after Tran et al., 2019 }\end{array}$ & $\# 11$ & $\begin{array}{l}\text { G2 OFF DS after Baden et al., 2016; } \\
\text { Putative F-mini OFF after Rousso et al., } \\
2017 ; \\
\text { Cluster 4 after Tran et al., 2019 }\end{array}$ \\
\hline$\# 5$ & $\begin{array}{l}\text { G10 W3 local edge detector after Baden et } \\
\text { al., 2016; Zhang et al., 2012; } \\
\text { Cluster 6 after Tran et al., 2019 }\end{array}$ & $\# 12$ & $\begin{array}{l}\text { G12 ON-OFF DS1 after Baden et al., } \\
2016 ; \\
\text { Nasal, ventral cluster 12, 16 after Tran et } \\
\text { al., 2019 }\end{array}$ \\
\hline$\# 6$ & $\begin{array}{l}\text { G22 ON sustained after Baden et al., } \\
\text { Putative PixON after Johnson et al., 2018 }\end{array}$ & $\begin{array}{l}\# 14 \\
\text { G16 trans after Baden et al., 2016 }\end{array}$ & $\begin{array}{l}\text { G14 ON-OFF local OS after Baden et al., } \\
2016\end{array}$ \\
\hline
\end{tabular}

Table 2: Summary of identified Scnn1a clusters and potential matches with existing literature. NB these are suggestions. 


\section{Discussion}

261 We established a novel approach for RGC classification, based on grouping of cells sharing 262 gene expression and similarities in their light response patterns. A previous study used 263 pharmacogenetics in combination with MEA recordings for Parvalbumin RGC classification 264 (33). PV expressing cells in the retina are manifold with at least 8 RGC types (26) and a distinct number of amacrine cells. Other approaches combined MEA recordings with anatomical imaging $(34,35)$. We successfully used a combination of all three methods, excitatory DREADD activation in retinal cells, immunohistochemistry and large-scale retinal electrophysiology to provide a significantly more comprehensive pan-retinal phenotypical description of Grik4- and Scnn1a-expressing RGCs in the mouse retina. Indeed, we extended the pre-existing list of Grik4 expressing RGC types, which validates our approach, and indicates that it has more powerful detection potential than previous ones. For the first time, we also provide a functional description of Scnn1a-expressing RGCs. We also showed that certain types of ACs express Grik4 and Scnn1a and that exciting these cells with DREADDs activation leads to spike firing change in many undefined RGCs. Our approach is not restricted to retinal cells but is widely applicable to other neurons from other brain regions. It is a scalable multimodal approach and can provide fast grouping of large cohorts of neurons with similar gene expression.

278 Grik4 expression in the retina has been described $(13,35-38)$ but there is functional 279 characterization only for two RGC types $(37,38)$. Johnson et al., $(38)$ reported that the Grik4280 expressing PixON RGC type is an ON sustained type and has strong spontaneous activity. 281 Our Grik4 cluster \#2 from the stationary RGCs (Tab 1) has the same key phenotypic features - sustained responses and strong spontaneous activity. Cluster \#2 also matches with the ON sustained group (G) 22 from Baden et al. 2016, (5). Grik4 clusters \#1, \#3 and \#4 potentially resemble G20 (ON high freq), G11 (ON-OFF local) and G5 (OFF alpha sustained) from that study. Cluster \#3 is potentially also resembling HD1/2 after Jacoby \& Schwartz 2017 (39) and 
286

287

288

289

290

291

292

293

294

295

296

297

298

299

300

301

302

303

304

305

306

307

308

309

310

311

312

the \#4 OFF alpha sustained is further described in Krieger et al. 2017, (40) The latter one is parvalbumin positive $(5,14,40)$ and in line with our IHC results that revealed Grik4 and parvalbumin expressing RGCs. Baden et al. (2016) found many more parvalbumin-expressing RGC types rather than the traditionally known 8 types (26). We suspect that there is some overlap between Grik4 and yet undescribed parvalbumin, potentially also calretinin, RGC types. We currently investigate the functional features of parvalbumin and calretinin coexpressing RGCs using a similar methodology (41). Further, the existence of Grik4-expressing ON-OFF - DS RGCs has been demonstrated in the mouse retina [22]. Cluster \#6 of our nonstationary RGCs also show ON-OFF DS RGCs (42) and potentially resemble G12 (ON-OFF DS1) from Baden et al. (2016) and the dorsal-temporal clusters 10, 16 and 24 after Tran et al., 2019 (6). Grik4 cluster \#8 is also G12 ON-OFF DS though the responses are less pronounced than in cluster \#6. Our non-stationary Grik4 cluster \#5 has similarities with G17 (ON local trans - OS) and cluster \#7 with G4 (OFF slow) from Baden et al. (2016). The latter one also shows similarities to the F-midi OFF cell responses described in Roussou et al. 2017, (43) and Tran et al. 2019, (6). It would also explain the findings of parvalbumin and calretinin positive Grik4 RGCs in our experiments (Fig 3 C) since F-midi OFF cells are supposed to express both (43).

For Scnn1a, we found seven stationary and seven non-stationary RGC response groups (Tab 2). Interestingly, the Scnn1a ON sustained Cluster \#7 showed remarkable similarity with the PixON characteristics described earlier - sustained responses and high baseline firing. There are no reports about Grik4 and Scnn1a co-expressing cells but it is not uncommon that certain RGC types share the same genes e.g. Foxp and Brn3 (43) or Pvalb and Calb2 $(41,43,44)$. Our Scnn1a stationary clusters \#1, \#2, \#3 and \#6 were grouped by gap statistics into 4 different groups but our post-hoc analysis (Fig 8 C, D) suggests one group. Therefore, these four clusters may reflect just one, or maybe two functional groups. They all exhibit ON transient responses but are not able to follow high frequencies in the chirp (like cluster \#1 in Grik4), thus they resemble G18 (ON trans) in Baden et al. (2016). Cluster \#4 has OFF transient 
response characteristics and could resemble G8 (OFF alpha trans, see also (40)) after Baden et al., 2016 and cluster 45 after Tran et al. 2019, (6). The Scnn1a stationary cluster \#5 shows weak ON and OFF responses to chirp and could potentially be the W3 local edge detector (G10 in Baden et al. 2016) (45). The grouping of the non-stationary Scnn1a clusters \#8 - \#14 shows a variety of response types. Scnn1a cluster \#8 shows strong ON transient and slight OS responses and may relate to G17 (ON trans OS) in Baden et al. (2016). Scnn1a cluster \#9 shows very weak and sluggish ON DS responses and is not really following the oscillating components in the chirp. It shows similarities to G26 (ON DS sust 2) from Baden et al. (2016). Our Scnn1a OFF DS cluster \#11 is most likely G2 (OFF DS) in Baden et al. (2016) and/or potentially the F-mini OFF described in Roussou et al. (2016) and Tran et al., 2019. The Fmini-OFF is calretinin (occasionally parvalbumin as well) positive which would fit with our IHC results. The non-stationary Scnn1a ON-OFF DS cluster \#12 may relate to G12 (ON-OFF DS 1) and nasal-ventral clusters $12 \& 16$ after Tran et al., 2019. Cluster \#13 is potentially G14 (ON-OFF local OS) from Baden et al. 2016. Clusters \#10 and \#14 show very weak chirp responses and it is difficult to assign them to any existing response type. In summary, our approach is able to group individually MEA recorded RGC response types into established response clusters (Baden et al. (2016 and Tran et al., 2019)) obtained with $\mathrm{Ca}^{2+}$ imaging or genetically, respectively.

DREADDs were also expressed in one or several yet undescribed AC types. For Scnn1a, we found few GABAergic ACs but most GFP-positive ACs were not characterized further. For Grik4, we did not find any GABAergic ACs, nor were we able to define the AC type with our experimental means. Excitatory activation of Grik4 and Scnn1a ACs does have a profound effect on postsynaptic RGC activity. A single AC affects nearly every RGC within reach of its dendrites (46). Briefly, assuming that CNO acts simultaneously on some ACs and RGCs, we are confronted with the problem of untangling the underlying circuits. For example, let us consider a simple network with one population of DREADD ACs which modulate one population of bipolar cells and one population of DREADD-RGCs. Adding CNO will have a 
340 direct effect on RGCs, increasing their activity (firing and/or bursting rate). At the same time,

341 ACs activity increases, thereby reinforcing lateral inhibition. This situation is already complex

342 enough if we consider non linearities in the cell's responses. But as those cells are embedded

343 in a network, the net effect of CNO can have many forms leading to a priori undetermined

344 situations. For example, it is known that cascade of inhibition can result in excitation (e.g.

345 push-pull effect) (47). A possible solution to this problem relies on a quantitative analysis that requires considering the factors constraining individual cell responses, without and with CNO,

347 and the network connectivity. It is possible to propose a map of CNO induced scenarios in

348 simple situations, with a suitable space of relevant biophysical parameters. These questions

349 will be addressed on modelling and mathematical grounds in a forthcoming paper.

350 Finding DREADD expression in ACs was initially challenging. We managed to circumvent the interference of DREADD activated ACs by combining MEA recordings with IHC, which is not a straightforward solution and renders experiments much more complex. Our experimental design was based on Cre-Lox recombination, resulting in DREADD expression in all cells with the same promoter gene in the organism. In future work, DREADD expression should be targeted only to RGCs via intraocular viral transfection in order to avoid such strong side effects (48). Blocking AC input onto postsynaptic targets (bipolar cells or RGCs) would be another solution but has a big caveat: such disinhibition leads to massive increase in activity levels in all RGCs, hence masking RGC specific DREADD activation in specific subgroups where DREADDs are directly expressed on RGCs.

\section{Methods}

Animals and retina preparation:

363 All experimental procedures were approved by the ethics committee at Newcastle University and carried out in accordance with the guidelines of the UK Home Office, under control of the

365 Animals (Scientific Procedures) Act 1986. Grik4 (C57BL/6-Tg(Grik4-cre)G32-4Stl/J, the 366 Jackson Laboratory, MA, JAX Stock No: 006474) and Scnn1a (B6;C3-Tg(Scnn1a-cre)3Aibs/J, 
JAX Stock No: 009613) mice were cross-bred with Gq-DREADD mice (B6N;129-Tg(CAGCHRM3* $^{*}-$ mCitrine)1Ute/J, JAX Stock No: 026220) to generate a strain of mice with the excitatory Gq-DREADD expressed in Grik4 and Scnn1a expressing cells (from here on named: Grik4-DREADD and Scnn1a-DREADD, respectively). In addition, we crossbred the Grik4 and Scnn1a lines with an inhibitory DREADD (B6.129-Gt(ROSA)26Sortm1(CAGCHRM4* ${ }^{*}$-mCitrine)Ute/J, JAX Stock No: 026219) but the effect on RGC firing rate was negligible and the litters were used only for immunofluorescence studies. Male and female wild-type, Grik4-DREADD and Scnn1a-DREADD mice, housed under a 12-hour light-dark cycle and aged between postnatal days (P) 53-148 were used for the experiments. Mice were dark-adapted overnight and killed by cervical dislocation. Eyes were enucleated, and following removal of the cornea, lens, and vitreous body, they were placed in artificial cerebrospinal fluid (aCSF) containing the following (in $\mathrm{mM}$ ): $118 \mathrm{NaCl}, 25 \mathrm{NaHCO}_{3}, 1 \mathrm{NaH}_{2} \mathrm{PO}_{4}, 3 \mathrm{KCl}, 1 \mathrm{MgCl}_{2}$, $2 \mathrm{CaCl}_{2}, 10$ glucose, and 0.5 I-Glutamine, equilibrated with $95 \% \mathrm{O}_{2}$ and $5 \% \mathrm{CO}_{2}$. The ventral and dorsal orientation was marked after enucleation. The retina was isolated from the eye cup and flattened for MEA recordings. For vertical cryosections, mouse eyecups were fixed in $4 \%$ paraformaldehyde (PFA; Alfa Aesar, MA) in $0.1 \mathrm{M}$ phosphate buffer solution (PBS) for $2 \times 20$ minutes at room temperature and washed with PBS several times. For whole mounts, retinas were isolated from the eye cup and mounted on nitrocellulose paper (Sartorius, Germany) and transferred to 4\% PFA in PBS $(2 \times 20 \mathrm{~min})$, rinsed in PBS and prepared for further procedures. All procedures involving live animals and retinas were performed in dim red light and the room was maintained in darkness throughout the experiment.

Immunohistochemistry and image acquisition:

After enucleation and fixation, the retinal tissue was processed in different ways for vertical and whole mount immunohistochemistry (IHC). For vertical sections, eyecups were cryoprotected in $30 \%$ sucrose in PBS overnight at $4^{\circ} \mathrm{C}$ and embedded in OCT Tissue TeK 393 (Sakura, $\mathrm{NL}$ ) at $-20^{\circ} \mathrm{C}$ on the following day. Vertical sections $(15-20 \mu \mathrm{m})$ were cut on a 
395 (Thermo Fisher). Vertical sections and whole mounts were blocked with $10 \%$ normal goat serum (NGS) and/or 10\% normal donkey serum (NDS) in PBS for at least 30 minutes at room

397 temperature.

398 After the blocking procedure and a short rinse in PBS, Vertical sections were incubated with primary antibodies in 5\% NGS (and/or NDS) $+1 \%$ Triton X-100 + PBS overnight at $4^{\circ} \mathrm{C}$. Whole mounts were incubated free-floating with primary antibodies in 5\% NGS (and/or NDS) $+1 \%$

401 Triton X-100 + PBS for $4-5$ days at $4^{\circ} \mathrm{C}$. Incubation with secondary antibodies in $1 \%$ Triton X-

402100 in PBS was carried out for 2 hours at room temperature for vertical sections or overnight 403 at $4^{\circ} \mathrm{C}$ for whole mounts. Details of the primary antibodies are as follows: anti-GFP (chicken, 404 Abcam 13970, 1:500-1000), anti-RBPMS (rabbit, Phosphosolutions 1830, $1: 1000$ ), anti-GABA 405 (mouse, Sigma Aldrich A0310, 1:1000), anti-Calretinin (mouse, Swant 6B3, 1:1000) and anti406 Parvalbumin (rabbit, Swant PV27, 1:1000). Secondary antibodies are as follows (all 407 concentrations 1:500): goat anti-chicken CF488, goat anti-rabbit Alexa568/Alexa647 and 408 donkey anti-mouse Alexa647. After washing several times with PBS, sections and whole 409 mounts were mounted in Vectashield (Vector Laboratories, UK). All incubations and washing 410 procedures were performed in the dark.

411 Images were captured using either a Zeiss Axio Imager upright microscope with Apotome 412 structured illumination fluorescence (using 20x/40x air objectives) or a Zeiss LSM800 confocal 413 microscope with 40x oil objective (Zeiss, Germany) operated with Zen software. Whole mount 414 images were stitched together using Zen software, all other image post processing was done 415 with Fiji (https://fiji.sc), Adobe Photoshop (Adobe, CA) and MATLAB (Mathworks, MA). The 416 steps between single sections of confocal stacks were not exceeding $1 \mu \mathrm{m}$ and 3 - 5 sections 417 were superimposed with Fiji for presentation. For the cell density maps, cells were manually 418 counted using the "Cell Counter" plugin in Fiji and a bivariate histogram (MATLAB hist3, bin 419 size $60 \times 60 \mu \mathrm{m}$ ) was calculated for the cell densities. For visualizing purposes, a 2-D Gaussian 420 filtering was applied (MATLAB imgaussfilt, sigma 3). 
Large-scale, high-density multielectrode array recordings and light stimulation:

423 Recordings were performed on the BioCamX platform with high-density-multielectrode array

424 (HD-MEA) Arena chips (3Brain $\mathrm{GmbH}$, Lanquart, Switzerland), integrating 4096 square microelectrodes in a $2.67 \times 2.67 \mathrm{~mm}$ area and aligned in a square grid with $42 \mu \mathrm{M}$ spacing. The isolated retina was placed, RGC layer facing down, onto the MEA chip and flattened by placing a small piece of translucent polyester membrane filter (Sterlitech Corp., Kent, WA, USA) on the retina followed by a home-made anchor. Retinas were maintained at $33^{\circ} \mathrm{C}$ using an in-line heater (Warner Instruments LLC, Hamden, CT, USA) and continuously perfused using a peristaltic pump ( 1 ml min-1). Retinas were left to settle on the MEA for at least 2 hours before recording. The platform records at a sampling rate of $\sim 18 \mathrm{kHz} /$ electrode when using the full $64 \times 64$ array. Recordings are filtered at $50 \mathrm{~Hz}$ high-pass filter using BrainWaveX software (3Brain) and stored in hdf5-based data format. Spikes were detected and sorted using Herdingspikes2 (https://github.com/mhhennig/HS2) as in (16). Briefly, spikes were first detected as threshold crossings individually on each channel, and then merged into unique events based on spatial and temporal proximity. For each detected spike, a location was estimated based on the signal centre of mass. Spike sorting was performed by clustering all events using a feature vector consisting of the locations and the first two principal components of the largest waveform.

Light stimuli were projected onto the retina as described elsewhere (17). Briefly, the projector 442 irradiance was attenuated using neutral density filters to mesopic light levels (white $4 \mu \mathrm{W} / \mathrm{cm}^{2}$ ).

443 For stimuli we used a full field 'chirp' stimulus consisting of various 1-sec contrast steps, 444 increasing frequency $(1-15 \mathrm{~Hz})$ and contrast modulations (1-93 Michelson contrast) which was 445 repeated 5 times. We also used random black and white moving bars (width $100 \mu \mathrm{M}, 12$ 446 directions $\left(30^{\circ}\right.$ separation) $), 800 \mathrm{~mm} / \mathrm{s}$, and the whole sequence repeated 5 times. For the 447 chirp and motion stimuli, we estimated each unit's instantaneous firing rate for the different 448 stimuli by convolving its spike train with a Gaussian kernel smoothing function (standard 449 deviation $(S D)=25 \mathrm{~ms}$ ). We then averaged the trials and extracted several features including 
bioRxiv preprint doi: https://doi.org/10.1101/2021.05.09 443323; this version posted July 8, 2021. The copyright holder for this preprint (which was not certified by peer review) is the author/funder, who has granted bioRxiv a license to display the preprint in perpetuity. It is made available under aCC-BY-NC-ND 4.0 International license. yields light responses from hundreds to thousands of individual RGCs.
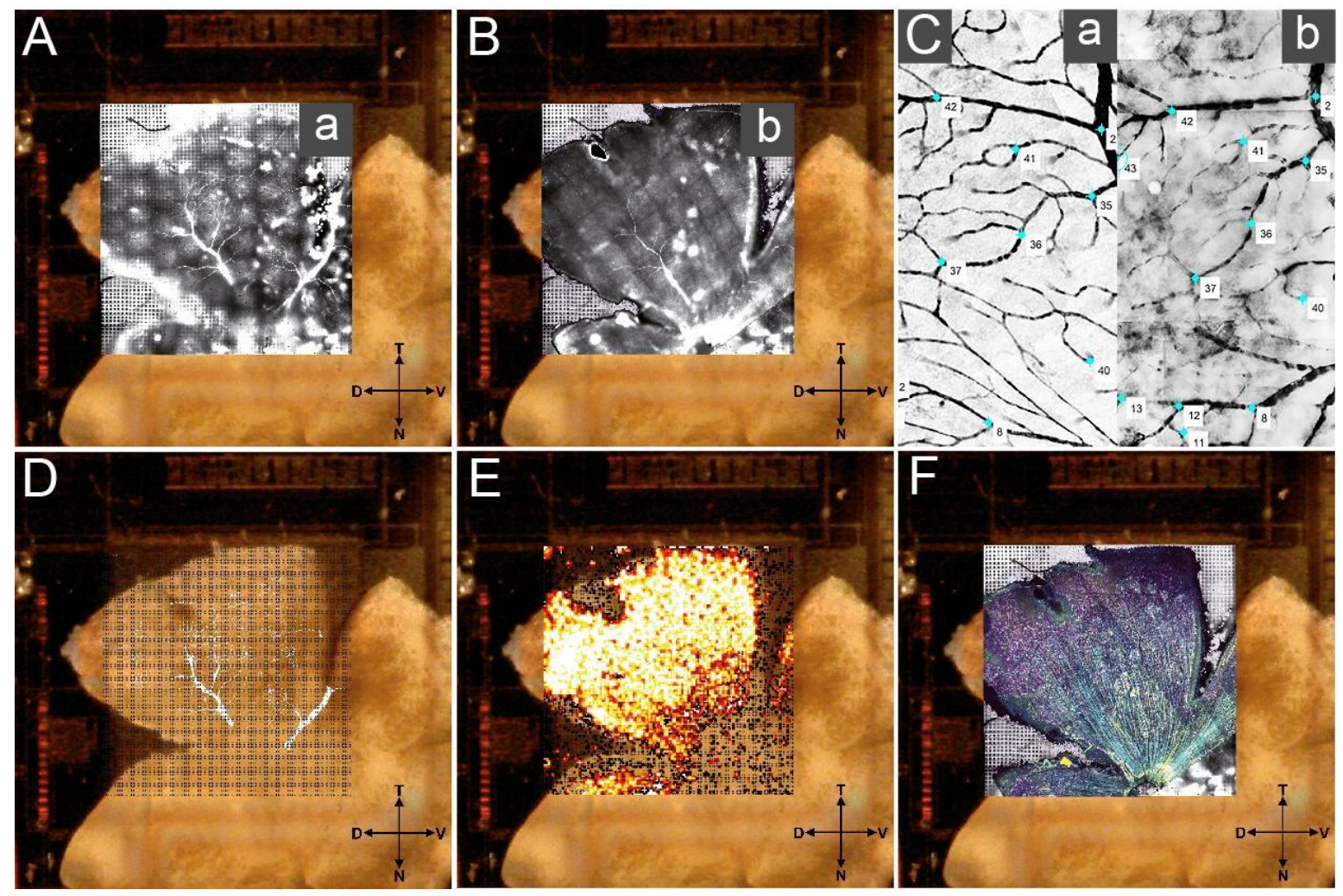

Figure 9: Registering spike location with cell labelling using blood vessel landmarks. Control points in the fixed pre-labelled $(\mathrm{A})$ and moving post-labelled $(\mathrm{B})$ blood vessel image were aligned ( $C$, insets $a \& b$ from $A$ and $B$, respectively) and the resulting transformation matrix (D) was fixed aligned with the spike locations (E) and additional immunostainings $(F)$. $D=$ dorsal; $V=$ ventral; $N=$ nasal; $T$ = temporal; Grid electrode size $2.65 \times 2.65 \mathrm{~mm}$

Registering RGC activity with IHC - blood vessels as reference marker:

To register RGC activity with IHC, we used pre- and post-labelled blood vessels as reference markers (Fig. 1). For pre-labelled blood vessel staining, the eye cup was incubated for $1 \mathrm{hr}$ in aCSF $+5 \mu \mathrm{M}$ Sulforhodamine 101 (SR101, Sigma Aldrich, MO) and afterwards transferred to aCSF $+0.06 \mu \mathrm{M}$ SR101 for MEA recording procedures. After recording, the weight and the polyester membrane were carefully removed to expose the retina, and the MEA well rinsed with aCSF. If the blood vessels were not visible, a 50\% Optiprep (Sigma Aldrich, MO) /50\% aCSF solution was used for rinsing and further clearing. The MEA chip was mounted on a 
2-3 min with oxygenated aCSF to ensure the tissue remains healthy throughout the procedure.

462 The best stained blood vessel layer (either superficial or deep vascular plexus) was meander-

463 like imaged (Fig. 9 A). For every captured blood vessel, images were acquired in the same

464 location all the way down to the electrodes as well. Neighbouring images were manually

465 stitched together in Adobe Photoshop (Adobe, CA) later. The retina was then carefully removed from the MEA, flattened on a nitrocellulose membrane for IHC procedure. Blood vessel staining was enhanced by using an anti-mouse secondary antibody in the same excitation spectrum (normally Alexa568) and blood vessels were imaged again (same plexus as while the retina was imaged on the MEA (Fig. 9 B). Both blood vessel staining images, preand post-tissue fixation were correlated with each other using the Control Point Selection Tool in Matlab (Fig. 9 C). Briefly, the images taken in the live retina on the MEA were used as the fixed (reference) image and images acquired post fixation as the moving image. Minimum 50 reference points were picked for the fixed and moving images to create a geometric transformation (Matlab fitgeotrans, Iwm, 50). That geometric transformation was applied to the GFP image. A stack (hereafter called MEA images) with the MEA electrode image, blood vessels pre- and post-fixation and GFP image was created in Adobe Photoshop (Fig. 9 F).

Registering RGC activity with IHC - Grik4/Scnn1a DREADD RGC identification:

The main procedure to identify and register RGC activity (spike clusters) with the MEA images is described in the main results (Figures 5, 9). Only units that did show a significant change in spontaneous firing rate (sampled during at least $5 \mathrm{~min}$ ) before and after adding CNO to the chamber were selected for Grik4/Scnn1a RGC identification and response clustering. Units with either $>50 \%$ or $<50 \%$ change in firing rate in CNO were considered as potential Grik4/Scnn1a candidates. We also used the Burst Index (32) to look at potential changes in activity levels induced by CNO, with potential Grik4/Scnn1a cells having changes in their Burst Index exceeding +/- 50\%. Only these selected RGCs were further identified in the next steps. 
489 for each detected spike from a single RGC unit is calculated (Figure $5 \mathrm{~B}$ ). The spike location

490 coordinates are given for a 64 x64 grid (the electrode layout of our MEA). Occasionally, we

491 confirmed the cluster centre (e.g., the centre of mass of negative spike amplitude peaks)

492 calculated by Herdingspikes2 by overlaying the $\mathrm{x}$ and $\mathrm{y}$ localization for the negative voltage

493 peak (Figure 5 C magenta diamond) obtained through electrical imaging. For electrical

494 imaging, the voltage fluctuations from the spike origin electrode and the neighbouring 7 electrode rows and columns were read out. For a minimum of 1000 spikes per RGC unit, voltage fluctuations before and after (here $5 \mathrm{~ms}$ ) each spike were normalized, and maximally

497 projected with absolute values (Figure $5 \mathrm{C}$ ) to visualize the current sink and the axonal trajectories. The spike localization and current sink coordinates were multiplied using a scaling factor to match the MEA images stack. GFP images were transformed to 8-bit images, a threshold (Matlab max entropy) was applied, potential gaps filled (Matlab imfill 'holes') and binarized (Matlab bwareaopen 50). Binary images were analyzed (Matlab regionprops), centroids and diameters for every potential GFP blob were calculated and the pairwise distance between centroids and spike locations was measured for all combinations.

Registering RGC activity with IHC - Grik4/Scnn1a response clustering: and grouped according to their response to a chirp stimulus. But before that grouping, cells were pre-classified into motion sensitive (responding preferably to either direction or orientation of motion) or cells that respond best to static stimuli (full field, chirp). We calculated

510 the direction (DSI) and orientation (OSI) selectivity index as described elsewhere (16) but used

511 a cut-off value for every experiment independently. Briefly, we fitted the tabulated data with a

512 mixture of two gaussians (Figure $6 \mathrm{~B}, \mathrm{E}$ ). The fit parameters were computed using maximum 513 likelihood parameter estimates (Matlab mle) and mu2 (the second peak, Figure 6 B, E) was 514 used as cut-off value. The trail variability and signal to noise ratio was calculated (16) for each 515 stationary/non-stationary RGC, and units with a value below the $25^{\text {th }}$ percentile were 516 discarded. The chirp responses of the remaining Grik4 and Scnn1a stationary/non-stationary 
517 RGC units were used to establish response groups. We used a similar approach to calculate

518 the SPIKE distance as described in our earlier work (10). Briefly, the SPIKE distances were

519 computed using the open-source package PYSPIKE (30). The pairwise distances between

520 two units were determined by computing the pairwise distances of all trials of the chirp

521

522

523

524

525

526

527

528

529

530

531

532

533

534

535

536

537

538

539

540

541

542

543

stimulus. The resulting distance matrix was then clustered with a hierarchical clustering algorithm (Python, Scipy library dendrogram). Matlab and Python scripts and other extended material will be made available via https://github.com/GerritHilgen/DREADD RGCclass.

\section{Acknowledgments}

This project was funded by the Leverhulme Trust (RPG-2016-315 to ES and BC), by Newcastle University (Faculty of Medical Sciences Graduate School and Pro-Vice Chancellor Discretionary Fund). We thank Matthias Hennig for help with the SPIKE distance calculations and Chris Williams who worked on related, unpublished aspects of the project. We also thank the Bioimaging Unit at Newcastle University for providing excellent service and help for this project.

\section{Authors' contributions}

Conceptualization: G.H., E.S., B.C.; Software: G.H. Methodology: G.H., E.S.; Formal Analysis: GH., Investigation, G.H., V.K., E.K.; Writing - Original Draft: G.H., E.S., B.C., V.K., J.K.; Project administration: E.S., B.C.; Funding Acquisition: E.S., B.C.

\section{Legends}

Figure 1: Grik4 and Scnn1a cells in the GCL are not homogeneously distributed. Whole mount antibody staining against Grik4 (A) and Scnn1a (B) DREADD GFP were imaged at the level of the GCL. All stained GFP cells were counted and the densities were calculated and presented in pseudocolours for 3 Grik4 (C) and Scnn1a (D) retinas. V= ventral, $T=$ temporal, $\mathrm{D}=$ dorsal, $\mathrm{N}=$ nasal. Scale bar $\mathrm{A}, \mathrm{B}=1 \mathrm{~mm}$; Scale bar $\mathrm{A}, \mathrm{B}$ insets $\|=100 \mu \mathrm{m}$. 
544 Figure 2: Grik4 and Scnn1a DREADD are expressed in RGCs and ACs. Vertical sections were

545 stained for Grik4 (A, C, cyan) and Scnn1a (B, D, cyan) GFP. Sections were further co-labelled

546 with RBPMS (A, B, magenta), a marker for RGCs, and GABA (C, D, magenta). INL = inner

547 nuclear layer, IPL = inner plexiform layer, $\mathrm{GCL}=$ ganglion cell layer. Scale bar in $\mathrm{D}=20 \mu \mathrm{m}$.

548 Figure 3: Grik4 and Scnn1a DREADD are expressed in multiple RGC types. Vertical sections

549 of Grik4 and Scnn1a retinas were triple stained A, B) for GFP (cyan), RBPMS (magenta) and

550 Calretinin (yellow) or C, D) GFP (cyan), Parvalbumin (magenta) and Calretinin (yellow). INL =

551 inner nuclear layer, $\mathrm{IPL}=$ inner plexiform layer, $\mathrm{GCL}=$ ganglion cell layer. Scale bar in $\mathrm{D}=20$

$552 \mu \mathrm{m}$.

553

554 Figure 4: DREADD activation leads to spike pattern changes in RGCs. DREADDs in RGCs

can be activated with Clozapine $\mathrm{N}$-oxide $(\mathrm{CNO})$ and lead to an increase in firing frequency $(\mathrm{A}$,

556 right half) and sometimes also in bursting activity (B, right half). Similar activities can be evoked with an "allround" AC neurotransmitter blocker $(\mathrm{C})$ without CNO. The cocktail contains: $2 \mu \mathrm{M}$

558 Strychnine (glycine receptor antagonist), $20 \mu \mathrm{M}$ Mecamylamine (nicotinic acetylcholine receptor antagonist), $20 \mu \mathrm{M}$ Bicuculline (GABA ${ }_{A}$ antagonist), $5 \mu \mathrm{M}$ CGP 55845 ((2S)-3-[[(1S) -1- (3,4-Dichlorophenyl)ethyl] amino -2- hydroxypropyl] (phenylmethyl) phosphinic acid hydrochloride, GABA $_{B}$ antagonist), $50 \mu \mathrm{M}$ TPMPA (1,2,5,6-Tetrahydropyridin-4-yl

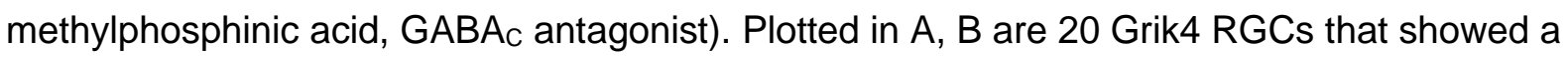
minimum of $50 \%$ change in firing frequency or bursting activity and in C 100 randomly selected Scnn1a RGC units. Control in A \& B means without CNO, in C without blockers. Vertical lines represent spike times plotted as a function of time.

567 Figure 5: Registering GFP RGCs with nearby isolated spike centre clusters. The spike cluster centre $(B$, circle) and electrical imaging $(C$, diamond) define the potential electrical source location of the isolated RGCs. Spike centres in close proximity to GFP labelled RGCs (D) were

570 registered as potential DREADD-expressing RGCs (E, F, Match). Scale bars $A, C, F=40 \mu m$; $571 \quad B=80 \mu m ; E=20 \mu m$. 
572 Figure 6: Dividing registered Grik4 and Scnn1a RGCs into stationary and non-stationary

573 responders. Moving stimuli were used to estimate the direction selectivity index (DSI) of

574 registered "Match" RGCs (Grik4 A, Scnn1a D, magenta). The DSI was plotted against the

575 probability density (histogram) and fitted with two gaussians (B, E, red line). RGCs exceeding 576 a set threshold (B, E, dotted red line) were labelled "non-Stationary". The registered RGCs

577 from all retinas were grouped into "non-Stationary" and "stationary" (C, F).

578

579 Figure 7: Clustering of Grik4 stationary and non-stationary RGC responses. RGC responses 580 that showed a high spike train similarity for a chirp stimulus $(B, F)$ were grouped together using 581 gap statistics (A). For each RGC of the groups, the PSTH was calculated and the mean PSTH 582 was plotted (B, F, coloured lines). The means for Bias Index (C, D, G), Response Duration (C), Baseline Spiking (D), Burst change (E), Spike Rate change (E) and orientation selectivity index (OSI, G) index were scatter plotted and their standard deviations were used as the circle diameters.

Figure 8: Clustering of Scnn1a stationary and non-stationary RGC responses. $R G C$ responses that showed a high spike train similarity for a chirp stimulus $(B, F)$ were grouped together using gap statistics (A). For each RGC of the groups, the PSTH was calculated and the mean PSTH was plotted (B, F, coloured lines). The means for Bias Index (C, D, G), Response Duration (C), Baseline Spiking (D), Burst change (E), Spike Rate change (E) and orientation selectivity index (OSI, G) index were scatter plotted and their standard deviations were used as the circle 593 diameters.

Figure 9: Registering spike location with cell labelling using blood vessel landmarks. Control points in the fixed pre-labelled (A) and moving post-labelled (B) blood vessel image were aligned ( $C$, insets $a \& b$ from $A$ and $B$, respectively) and the resulting transformation matrix

598 (D) was fixed aligned with the spike locations $(E)$ and additional immunostainings $(F) . D=$ 599 dorsal; $V$ = ventral; $N=$ nasal; T = temporal; Grid electrode size $2.65 \times 2.65 \mathrm{~mm}$ 
bioRxiv preprint doi: https://doi org/10.1101/2021.05.09.443323: this version posted July 8.2021 . The copyriaht holder for this preprint (which was not certified by peer review) is the author/funder, who has granted bioRxiv a license to display the preprint in perpetuity. It is made available under aCC-BY-NC-ND 4.0 International license.

600 Table 1: Summary of identified Grik4 clusters and potential matches with existing literature.

601 NB these are suggestions.

602

603 Table 2: Summary of identified Scnn1a clusters and potential matches with existing literature.

604 NB these are suggestions.

605

\section{References}

1. Euler T, Haverkamp S, Schubert T, Baden T. Retinal bipolar cells: elementary building blocks of vision. Nat Rev Neurosci. 2014 Aug;15(8):507-19.

2. Curcio CA, Allen KA. Topography of ganglion cells in human retina [Internet]. Vol. 300, The Journal of Comparative Neurology. 1990. p. 5-25. Available from:

http://dx.doi.org/10.1002/cne.903000103

3. Jeon C-J, Strettoi E, Masland RH. The Major Cell Populations of the Mouse Retina [Internet]. Vol. 18, The Journal of Neuroscience. 1998. p. 8936-46. Available from: http://dx.doi.org/10.1523/jneurosci.18-21-08936.1998

4. Masland $\mathrm{RH}$. The fundamental plan of the retina. Nat Neurosci. 2001 Sep;4(9):877-86.

5. Baden T, Berens P, Franke K, Román Rosón M, Bethge M, Euler T. The functional diversity of retinal ganglion cells in the mouse. Nature. 2016 Jan 21;529(7586):345-50.

6. Tran NM, Shekhar K, Whitney IE, Jacobi A, Benhar I, Hong G, et al. Single-Cell Profiles of Retinal Ganglion Cells Differing in Resilience to Injury Reveal Neuroprotective Genes. Neuron. 2019 Dec 18;104(6):1039-55.e12.

7. Coombs J, van der List D, Wang G-Y, Chalupa LM. Morphological properties of mouse retinal ganglion cells. Neuroscience. 2006 Jun 19;140(1):123-36.

8. Völgyi B, Chheda S, Bloomfield SA. Tracer coupling patterns of the ganglion cell subtypes in the mouse retina. J Comp Neurol. 2009 Feb 10;512(5):664-87.

9. Zeck GM, Masland $\mathrm{RH}$. Spike train signatures of retinal ganglion cell types. Eur $\mathrm{J}$ Neurosci. 2007 Jul;26(2):367-80.

10. Jouty J, Hilgen G, Sernagor E, Hennig MH. Non-parametric Physiological Classification of Retinal Ganglion Cells in the Mouse Retina. Front Cell Neurosci. 2018 Dec 7;12:481.

11. Sanes JR, Masland $\mathrm{RH}$. The types of retinal ganglion cells: current status and implications for neuronal classification. Annu Rev Neurosci. 2015 Jul 8;38:221-46.

12. Rheaume BA, Jereen A, Bolisetty M, Sajid MS, Yang Y, Renna K, et al. Single cell transcriptome profiling of retinal ganglion cells identifies cellular subtypes. Nat Commun. 2018 Jul 17;9(1):2759.

13. Martersteck EM, Hirokawa KE, Evarts M, Bernard A, Duan X, Li Y, et al. Diverse Central Projection Patterns of Retinal Ganglion Cells. Cell Rep. 2017 Feb 21;18(8):2058-72. 
bioRxiv preprint doi: https://doi.org/10.1101/2021.05.09.443323: this version posted July 8.2021 . The copyriaht holder for this preprint (which was not certified by peer review) is the author/funder, who has granted bioRxiv a license to display the preprint in perpetuity. It is made available under aCC-BY-NC-ND 4.0 International license.

14. Laboissonniere LA, Goetz JJ, Martin GM, Bi R, Lund TJS, Ellson L, et al. Molecular signatures of retinal ganglion cells revealed through single cell profiling. Sci Rep. 2019 Oct 31;9(1):15778.

15. Marblestone* AH, Zamft* BM, Maguire YG, Shapiro MG, Cybulski TR, Glaser Jl, et al. Physical principles for scalable neural recording. Front Comput Neurosci [Internet]. 2013 [cited 2021 Apr 5];7. Available from: https://www.frontiersin.org/articles/10.3389/fncom.2013.00137/pdf

16. Hilgen G, Pirmoradian S, Pamplona D, Kornprobst P, Cessac B, Hennig MH, et al. Panretinal characterisation of Light Responses from Ganglion Cells in the Developing Mouse Retina. Sci Rep. 2017 Feb 10;7:42330.

17. Portelli G, Barrett JM, Hilgen G, Masquelier T, Maccione A, Di Marco S, et al. Rank Order Coding: a Retinal Information Decoding Strategy Revealed by Large-Scale Multielectrode Array Retinal Recordings. eNeuro [Internet]. 2016 May;3(3). Available from: http://dx.doi.org/10.1523/ENEURO.0134-15.2016

18. Nakazawa K, Quirk MC, Chitwood RA, Watanabe M, Yeckel MF, Sun LD, et al. Requirement for hippocampal CA3 NMDA receptors in associative memory recall. Science. 2002 Jul 12;297(5579):211-8.

19. Madisen L, Zwingman TA, Sunkin SM, Oh SW, Zariwala HA, Gu H, et al. A robust and high-throughput Cre reporting and characterization system for the whole mouse brain. Nat Neurosci. 2010 Jan;13(1):133-40.

20. Armbruster BN, Li X, Pausch MH, Herlitze S, Roth BL. Evolving the lock to fit the key to create a family of $G$ protein-coupled receptors potently activated by an inert ligand. Proc Natl Acad Sci U S A. 2007 Mar 20;104(12):5163-8.

21. Roth BL. DREADDs for Neuroscientists. Neuron. 2016 Feb 17;89(4):683-94.

22. Urban DJ, Roth BL. DREADDs (designer receptors exclusively activated by designer drugs): chemogenetic tools with therapeutic utility. Annu Rev Pharmacol Toxicol. 2015;55:399-417.

23. Zhu H, Aryal DK, Olsen RHJ, Urban DJ, Swearingen A, Forbes S, et al. Cre-dependent DREADD (Designer Receptors Exclusively Activated by Designer Drugs) mice. Genesis. 2016 Aug;54(8):439-46.

24. Rodriguez AR, de Sevilla Müller LP, Brecha NC. The RNA binding protein RBPMS is a selective marker of ganglion cells in the mammalian retina [Internet]. Vol. 522, Journal of Comparative Neurology. 2014. p. 1411-43. Available from: http://dx.doi.org/10.1002/cne.23521

25. Lee E-S, Lee J-Y, Jeon C-J. Types and density of calretinin-containing retinal ganglion cells in mouse. Neurosci Res. 2010 Feb;66(2):141-50.

26. Yi C-W, Yu S-H, Lee E-S, Lee J-G, Jeon C-J. Types of parvalbumin-containing retinotectal ganglion cells in mouse. Acta Histochem Cytochem. 2012 Jun 28;45(3):201-10.

27. Verbist C, Müller MG, Mansvelder HD, Legenstein R, Giugliano M. The location of the axon initial segment affects the bandwidth of spike initiation dynamics. PLoS Comput Biol. 2020 Jul;16(7):e1008087. 
bioRxiv preprint doi: https://doi org/10.1101/2021.05.09.443323: this version posted July 8.2021 . The copyriaht holder for this preprint (which was not certified by peer review) is the author/funder, who has granted bioRxiv a license to display the preprint in perpetuity. It is made available under aCC-BY-NC-ND 4.0 International license.

28. Colbert $\mathrm{CM}$, Johnston $\mathrm{D}$. Axonal action-potential initiation and $\mathrm{Na}+$ channel densities in the soma and axon initial segment of subicular pyramidal neurons. J Neurosci. 1996 Nov 1;16(21):6676-86.

29. Kreuz T, Chicharro D, Houghton C, Andrzejak RG, Mormann F. Monitoring spike train synchrony. J Neurophysiol. 2013 Mar;109(5):1457-72.

30. PySpike-A Python library for analyzing spike train synchrony. SoftwareX. 2016 Jan $1 ; 5: 183-9$.

31. Tibshirani R, Walther G, Hastie T. Estimating the number of clusters in a data set via the gap statistic. J R Stat Soc Series B Stat Methodol. 2001;63(2):411-23.

32. Jones TA, Leake PA, Snyder RL, Stakhovskaya O, Bonham B. Spontaneous discharge patterns in cochlear spiral ganglion cells before the onset of hearing in cats. $J$ Neurophysiol. 2007 Oct;98(4):1898-908.

33. Drinnenberg A, Franke F, Morikawa RK, Jüttner J, Hillier D, Hantz P, et al. How Diverse Retinal Functions Arise from Feedback at the First Visual Synapse. Neuron. $2018 \mathrm{Jul}$ 11;99(1):117-34.e11.

34. Li PH, Gauthier JL, Schiff M, Sher A, Ahn D, Field GD, et al. Anatomical identification of extracellularly recorded cells in large-scale multielectrode recordings. J Neurosci. 2015 Mar 18;35(11):4663-75.

35. Pisano F, Zampaglione E, McAlinden N, Roebber J, Dawson MD, Mathieson K, et al. Large scale matching of function to the genetic identity of retinal ganglion cells. Sci Rep. 2017 Nov 13;7(1):15395.

36. Ivanova E, Hwang G-S, Pan Z-H. Characterization of transgenic mouse lines expressing Cre recombinase in the retina. Neuroscience. 2010 Jan 13;165(1):233-43.

37. Rivlin-Etzion M, Zhou K, Wei W, Elstrott J, Nguyen PL, Barres BA, et al. Transgenic mice reveal unexpected diversity of on-off direction-selective retinal ganglion cell subtypes and brain structures involved in motion processing. J Neurosci. 2011 Jun 15;31(24):8760-9.

38. Johnson KP, Zhao L, Kerschensteiner D. A Pixel-Encoder Retinal Ganglion Cell with Spatially Offset Excitatory and Inhibitory Receptive Fields. Cell Rep. 2018 Feb 6;22(6):1462-72.

39. Jacoby J, Schwartz GW. Three Small-Receptive-Field Ganglion Cells in the Mouse Retina Are Distinctly Tuned to Size, Speed, and Object Motion. J Neurosci. 2017 Jan 18;37(3):610-25.

40. Krieger B, Qiao M, Rousso DL, Sanes JR, Meister M. Four alpha ganglion cell types in mouse retina: Function, structure, and molecular signatures. PLoS One. 2017 Jul 28;12(7):e0180091.

41. Hilgen G, Lockwood E, Ratcliff JEJ, Sernagor E. Pan-retinal characterization of parvalbumin-calretinin co-expressing cells in the mouse retina. F1000Res [Internet]. 2019 Sep 9 [cited 2021 Apr 28];8. Available from: http://dx.doi.org/10.7490/f1000research.1117479.1

42. Vaney DI, Sivyer B, Taylor WR. Direction selectivity in the retina: symmetry and asymmetry in structure and function. Nat Rev Neurosci. 2012 Feb 8;13(3):194-208. 
43. Rousso DL, Qiao M, Kagan RD, Yamagata M, Palmiter RD, Sanes JR. Two Pairs of ON and OFF Retinal Ganglion Cells Are Defined by Intersectional Patterns of Transcription Factor Expression. Cell Rep. 2016 May 31;15(9):1930-44.

44. Kovács-Öller T, Szarka G, Tengölics ÁJ, Ganczer A, Balogh B, Szabó-Meleg E, et al. Spatial Expression Pattern of the Major Ca-Buffer Proteins in Mouse Retinal Ganglion Cells. Cells [Internet]. 2020 Mar 25;9(4). Available from:

http://dx.doi.org/10.3390/cells9040792

45. Zhang Y, Kim I-J, Sanes JR, Meister M. The most numerous ganglion cell type of the mouse retina is a selective feature detector. Proc Natl Acad Sci U S A. 2012 Sep 4;109(36):E2391-8.

46. de Vries SEJ, Baccus SA, Meister M. The projective field of a retinal amacrine cell. J Neurosci. 2011 Jun 8;31(23):8595-604.

47. Deny S, Ferrari U, Macé E, Yger P, Caplette R, Picaud S, et al. Multiplexed computations in retinal ganglion cells of a single type. Nat Commun. $2017 \mathrm{Dec}$ 6;8(1):1964.

48. Storchi R, Milosavljevic N, Eleftheriou CG, Martial FP, Orlowska-Feuer P, Bedford RA, et al. Melanopsin-driven increases in maintained activity enhance thalamic visual response reliability across a simulated dawn. Proc Natl Acad Sci U S A. 2015 Oct 20;112(42):E5734-43. 